\title{
Evolution of Computer-Aided Process Planning for Hybrid Additive/Subtractive Process
}

\author{
Osama Abdulhameed (D), 1,2 Abdulrahman Al-Ahmari, 1,2 Syed Hammad Mian, \\ Abdulmajeed Dabwan $\mathbb{D}^{2}{ }^{2}$ and Hisham Alkhalefah ${ }^{1}$ \\ ${ }^{1}$ Raytheon Chair for Systems Engineering (RCSE Chair), Advanced Manufacturing Institute, King Saud University,
Riyadh 11421, Saudi Arabia
${ }^{2}$ Industrial Engineering Department, College of Engineering, King Saud University, Riyadh 11421, Saudi Arabia
}

Correspondence should be addressed to Osama Abdulhameed; oabdulhameed@ksu.edu.sa

Received 14 April 2020; Revised 20 May 2020; Accepted 1 June 2020; Published 18 July 2020

Academic Editor: Aniello Riccio

Copyright (C) 2020 Osama Abdulhameed et al. This is an open access article distributed under the Creative Commons Attribution License, which permits unrestricted use, distribution, and reproduction in any medium, provided the original work is properly cited.

\begin{abstract}
The hybrid process, which integrates two or more different processes such as additive manufacturing and subtractive manufacturing, has gained appreciable considerations in recent years. This process exploits the benefits of individual processes while overcoming their limitations. Lately, the combination of additive, subtractive, and inspection methods is a valuable conglomeration, considering its potential to produce complicated components precisely. Certainly, computer-aided process plan (CAPP) provides a crucial link among different processes and is essential to avail the benefits of hybridization. However, a valuable process plan can only be achieved through the optimization of its different elements. Therefore, the objective of this work is the accomplishment of an optimized CAPP to fabricate parts in the shortest time employing the hybrid additive, subtractive, and inspection processes. In this work, mathematical models have been developed to optimize part orientation as well as minimize additive and subtractive times. Additionally, the genetic algorithm has been employed to obtain the best path with minimum inspection time. The feasibility and capability of the proposed approach as well as the optimized CAPP for the hybrid process have been demonstrated through a case study.
\end{abstract}

\section{Introduction}

The growth and development of the manufacturing business depend on the ingenious studies related to the optimized utilization of manufacturing processes, materials, and product design. The highly competitive market, as well as the requirements of complex and accurate parts at a reasonable price, has given rise to the concept of hybridization. The hybrid manufacturing (HM) can be described as the fabrication approach, wherein the combination of manufacturing processes is integrated. HM helps to enhance the performance of individual processes while providing a compounded advantage from these processes. It is crucial to figure out the principles, advantages, and shortcomings of discrete processes for realizing HM. In recent times, the hybridization of additive and subtractive manufacturing is the most demanding due to its numerous benefits.
A subtractive manufacturing (SM) process such as computer numerical controlled (CNC) material removal machine can be integrated with the additive manufacturing (AM) process to overcome the constraints such as tool inaccessibility, higher error, degraded surface conditions, and lower building rate [1]. The combinations of AM and SM processes are increasingly being used to enhance manufacturing performance in terms of higher tool life, lower building time, effective machining with close tolerances, and enhanced surface finish. Although HM exhibits many benefits, its applications are limited as a result of the scarcity of computer-aided process plan (CAPP) approaches. Moreover, the few CAPPs which are existing have not been optimized to achieve effective and efficient HM. Indeed, the research works have so far focused on improving the individual processes instead of applying a comprehensive and universal perspective to optimize $\operatorname{HM}[2,3]$. 
Consequently, an effective and efficient CAPP is needed to be developed which can effectively shorten the fabrication time. As reported by many researchers, there is a significant lack of CAPP techniques, which can adequately utilize manufacturing resources to accomplish hybridization.

This work develops a hybrid process integrating AM, $\mathrm{SM}$, and the measurement process. A new process-planning system has been proposed for the production of prismatic parts in the shortest manufacturing time. The developed CAPP would provide enough flexibility to adapt to any modifications in production assets, machining settings, etc. on the working area as well as allow minimization of part production time. In this work, the CAPP has been optimized to improve the hybridization of AM, SM, and the inspection processes. The mathematical models have been developed to obtain the best part orientation as well as minimize the additive and subtractive times. Additionally, the genetic algorithm (GA) has been implemented to achieve the best path with minimum inspection time. A case study has also been discussed to depict the performance of the optimized CAPP in the hybrid process.

\section{Literature Review}

AM parts usually possess a poor surface quality; therefore, they are machined to produce the smooth surface finish. AM process can be integrated with the SM process to produce the finely finished parts. Largely, CNC milling is the frequently used procedure to process the near-net shapes obtained from AM. This is because the flat surface obtained using an uncomplicated rotary-tool polishing or grinding does not meet the norms needed for precise and accurate parts [4]. Therefore, advanced postprocessing using CNC polishing and milling, ultrasonic machining, glass blasting, etc. are required to produce finely finished parts [5]. There have been numerous efforts, where AM and SM have been combined to overcome the limitations of each other. Karunakaran et al. [6] explored the benefits of hybridization between CNC and AM. They combined a CNC machine and arc weld deposition to enhance the quality of the product and reduce production span and overall manufacturing cost. In the proposed setup, the layers were accumulated using metal inert-active gas welding and three-axis milling was employed to obtain the finely finished surfaces. LUMEX represented a single setup, which combined a fiber laser for metal sintering and a machining center for high accuracy and high-speed milling [7]. This system could fabricate complicated mold dies in lesser time and reduced production cost. Similarly, Kulkarni and Dutta [8] overcame the limitations of AM and SM processes through an integrated production setup. A hybrid process based on the integration of selective laser melting and CNC milling was employed by Kashouty et al. [9] to achieve desired accuracy and precision in the manufacture of an automobile tool insert. To comprehend the benefits of HM, Ren et al. [10] introduced a unified process-planning system considering a single setup combining AM and SM. It consisted of the extraction of information from the computer-aided design (CAD) model, optimization of the tool path, and collision detection algorithms. Liou et al. [11] and Ruan et al. [12] also developed a process-planning approach for laser sintering and $\mathrm{CNC}$ machining. Their approach was based on dividing the parts in nonuniform layer thickness and accomplishing collision-free tool paths.

Few works that focused on optimizing the process plans can also be pointed out in the literature. Although, there has been a significant scarcity of optimized process plans for hybrid processes. Most of the efforts directed to the optimization of process plans were dedicated to individual processes or manufacturing systems. For instance, Shabaka and ElMaraghy [13] developed a GA-based approach to optimize the manufacturing cost of the process plans in reconfigurable manufacturing systems (RMSs). The researchers identified various parameters such as machine appointment, machine structure, operation order, operation cluster sequencing, selected tools, and tool approach directions (TADs) of the operations, etc., to obtain the mathematical models. Likewise, Jia et al. [14] utilized the object-oriented representation to accomplish manufacturing information, process decision insight, and decision procedure control knowledge. Some works that have concentrated on the optimization of process plans for the hybrid process can also be listed out. Ahsan et al. [15] developed an innovative two-step optimization methodology to figure out the appropriate build direction for the object and material accumulation direction for layers. They considered the lowest contour plurality, surface characteristics, build height, fabrication parameter, and layer contour concavity to overcome the limitations associated with fabrication and resource availability. The developed methodology was carried out on a case study, and the outcomes indicated a significantly reduced total build time in contrast to the total build time related to subjective build and deposition directions. Similarly, Um et al. [16] proposed a description method of HM and developed process plans at both macroand microlevels. The stereolithography (STL) data, which are utilized to fabricate the part by AM, comprise a large number of errors, owing to several geometric processes. Therefore, the representation of solid models utilizing the Standard for the Exchange of Product model data (STEP) maintains the error as low as possible during geometric reasoning. The realization of geometric reasoning makes the process of planning automated with high accuracy. Moreover, Le et al. [17] demonstrated the utility of aggregating two technologies. The proposed approach aimed at reusing existent parts directly to produce final parts, evading the material recycling stage. This paper particularly aimed at designing the process plan for a composite AM and SM processes. Aboutaleb et al. [18] proposed an integrated framework to systematically accomplish suitable fused filament fabrication (FFF) process parameters, which resulted in optimal geometry integrity. The developed method was verified through a real-world case study. The outcome confirmed that optimal properties were attained more efficiently as compared to other existing methods. Reiher and Koch [19] considered part orientation as well as quality management guidelines to accomplish a suitable production plan. They showed numerous methods and measures to 
attain product optimization, information acquisition, decision-making, and shape identification for part optimization in AM. Udroiu and Nedelcu [20] proposed an optimization approach which aimed at three AM applications. The first application was the part orientation considering the minimum build time, minimum support structure, and surface accuracy. The second application was targeted at fitted validation of parts obtained using threedimensional (3D) printing. The study by Byun and Lee [21] aimed at the recognition of optimal buildup direction for different rapid prototyping (RP) systems. The computation of surface quality considered the layering effect, building time and part cost, labor cost rate, material cost, etc. The developed algorithm was utilized to obtain the most appropriate buildup direction and generate an optimal process planning.

Certainly, the research studies presented above have contributed immensely to the literature on hybrid techniques and their process planning. However, as shown in Table 1, these works were adequate and acceptable, but they were not all-inclusive as well as limited in their utilization. Moreover, there has been a dearth of research works that have focused on the development of optimization approaches for process planning of hybrid additive and subtractive manufacturing methods. There has always been a requirement to develop an optimized CAPP system for the hybrid process that can adjust to volatile machining conditions. Therefore, in this work, an optimized CAPP has been proposed to fabricate parts in the shortest time utilizing the hybrid additive, subtractive, and inspection processes. The mathematical models have been employed to optimize part orientation as well as minimize additive and subtractive times. Besides, the GA has been utilized to obtain the best path with minimum inspection time.

\section{Methodology}

The methodology proposed in this work would enhance the product quality as well as reduce the manufacturing costs. The scheme explained in Figure 1 represents specifically a generic overview of the hybrid additive, subtractive, and inspection system.

3.1. Feature Extraction and Recognition. A rational consistent feature recognition approach has been employed to achieve feature recognition. This system possesses the competence to communicate with hybrid additive, subtractive, and inspection systems. The proposed methodology has been introduced for $3 \mathrm{D}$ prismatic parts designed by a solid modeling package (CATIA V5). The system considers a neutral file in STEP format as input and then interprets the information in the file to the manufacturing information. The ISO 10303 STEP Standards AP 203 E2 file has been utilized. The steps of the feature extraction and recognition methodology are as follows:

Step 1. Obtain the geometry and topology items for the designed model using STEP file format.
Step 2. Obtain topology items in each basic surface and determine its type.

Step 3. Verify the feature's presence in the basic surface depending on loops.

Step 4. Determine feature type.

Step 5. Determine the detailed features and obtain the related feature geometry parameters.

Step 6. Determine the comprehensive machining data for each feature and the designed part.

The sample output of a feature extraction file that contains a feature ID, feature name, feature face IDs, and feature dimensions is shown in Table 2.

The rule-based approach as reported in [26] was adopted in this work to recognize the SM features. The following example represents the rule for recognizing the pocket through feature:

(1) For every 4 faces of the surface type plane (named as face 1 , face 2 , face 3 , and face 4 ) as shown in Figure 2(a).

(2) If concave edge count of the outer loop equals 2 for each face.

2.1. If each consecutive pair of faces (F1F2, F2F3, $\mathrm{F} 3 \mathrm{~F} 4$, and $\mathrm{F} 4 \mathrm{~F} 1$ ) has one common concave edge of type Line and the pair of faces is perpendicular to each other.

2.1.1. Pocket through found.

2.1.2. Create a new pocket through object and add to the feature list.

(3) End For

For inspection, the data such as faces, edges, and vertices in the extraction file were classified and listed on the basis of their type and angles. Dimensional tolerances (DTs) were calculated from the direct limits of the extracted feature's faces plus/minus tolerance values. For example, the feature length was calculated as the difference between F3 and F5, etc., as shown in Table 3 and Figure 2(b).

3.2. Part Orientation. The orientation rules for the improved surface accuracy depend on the relative orientation of various features/entities (in the extraction file) concerning the build direction. The extracted face orientation can be parallel, perpendicular, or at some angle. To satisfy better Geometric Dimensioning and Tolerancing (GD\&T) [24], the objective functions of the optimal orientation of the part were modeled. The objective functions were the maximization of GD\&T values and the minimization of production time. The automatic setup generation was achieved by gathering information from the feature extraction and recognition file as shown in Figure 3.

In this diagram (Figure 3), the setup class is consisted of get these methods, get all feature's faces, get all part faces, remove interaction faces, generate frequency interaction edges, generate probe feature accessibility, and make feature clustering. The face class has consisted of get face ID, get face 
TABLE 1: Distinction of present contribution in comparison to recent related works.

\begin{tabular}{|c|c|c|}
\hline \multicolumn{2}{|r|}{ Recent related research work } & \multirow[t]{2}{*}{ Current work } \\
\hline Reference & Contribution and limitations & \\
\hline Kamrani et al. [22] & $\begin{array}{l}\text { A framework was developed to generate an instruction } \\
\text { file for guiding the CMM measurement process. This } \\
\text { work primarily emphasized on developing a computer- } \\
\text { aided process plan for the inspection process. The feature } \\
\text { extraction, feature recognition, and probe approach } \\
\text { directions were utilized for ease of access, setup planning, } \\
\text { and inspection point's distribution on the measurand. } \\
\text { The techniques such as the clustering algorithm, } \\
\text { graphical method, and ANNs were used to carry out the } \\
\text { competent inspection. The proposed approach was } \\
\text { effective and competent, but it did not deal with the } \\
\text { manufacturing aspects. The stated process plan did not } \\
\text { consolidate the manufacturing processes, such as additive } \\
\text { and subtractive processes. }\end{array}$ & $\begin{array}{l}\text { This work is distinctive because it integrates additive, } \\
\text { subtractive, and inspection processes. The proposed } \\
\text { CAPP is holistic and comprehensive, which incorporates } \\
\text { manufacturing as well as inspection information in the } \\
\text { detailed process plan. The plan is flexible to adjust to any } \\
\text { changes in production resources, machining, and } \\
\text { inspection settings, etc. }\end{array}$ \\
\hline $\begin{array}{l}\text { Homar and } \\
\text { Pušavec [23] }\end{array}$ & $\begin{array}{l}\text { A processing time- and cost-oriented algorithm was } \\
\text { reported to minimize the fraction of the component that } \\
\text { has to be fabricated additively. A novel algorithm based } \\
\text { on an optimized manufacturing operation sequence was } \\
\text { utilized for feature recognition in hybrid processing } \\
\text { (subtractive and additive). The authors presented an } \\
\text { ingenious concept but did not recognize inspection, } \\
\text { which has now become an integral link in the production } \\
\text { process. Furthermore, this approach can be inefficient if } \\
\text { the part is very complex and the product requires an } \\
\text { additive process for the majority of its features. }\end{array}$ & $\begin{array}{l}\text { In this work, the inspection activity has been an } \\
\text { indispensable element of the entire methodology. The } \\
\text { additive, subtractive, and inspection processes have been } \\
\text { synchronized to attain an efficient process plan. The } \\
\text { established approach is formative and can be utilized for } \\
\text { prismatic parts with any complexity. }\end{array}$ \\
\hline $\begin{array}{l}\text { Al-Ahmari et al. } \\
{[24]}\end{array}$ & $\begin{array}{l}\text { The relationship between the attribute and build } \\
\text { orientation was studied in this work. An optimal part } \\
\text { orientation system was established to improve part } \\
\text { quality/accuracy in additive manufacturing. In this } \\
\text { approach, the weighted sum function was employed to } \\
\text { compute the part volume and time required for printing. } \\
\text { This work was enlightening, but it was limited only to } \\
\text { additive manufacturing and didn't describe the proposed } \\
\text { algorithm for its application in hybrid additive- } \\
\text { subtractive-inspection process. }\end{array}$ & $\begin{array}{l}\text { The existent research incorporated and unified the } \\
\text { developed mathematical models to enhance the } \\
\text { effectiveness of the extensive process plan for the hybrid } \\
\text { additive-subtractive-inspection process. }\end{array}$ \\
\hline $\begin{array}{l}\text { Abdulhameed } \\
\text { et al. [25] }\end{array}$ & $\begin{array}{l}\text { The concept of the multiagent system was proposed to } \\
\text { develop a computer-aided process plan for the hybrid } \\
\text { additive-subtractive-inspection process. It was based on a } \\
\text { three-step methodology, namely, a static process plan, } \\
\text { selection of optimum scenario, and dynamic process } \\
\text { plan. The crux of this work was the application of agent } \\
\text { theory in acquiring a proficient computer-aided process } \\
\text { plan for the hybrid process. However, this work did not } \\
\text { describe the optimization of individual phases. Although } \\
\text { the inspection was an integral part of their methodology, } \\
\text { the minimization of inspection time was not considered. } \\
\text { Moreover, this work primarily focused on the software } \\
\text { front and did not present the actual setup for hybrid }\end{array}$ & $\begin{array}{l}\text { The present work has also introduced a computer-aided } \\
\text { process plan for the hybrid additive-subtractive- } \\
\text { inspection process, but it does not consider the agent } \\
\text { theory. Instead, the idea of peaks is implemented to slice } \\
\text { the entire part to subpart. Moreover, the optimization of } \\
\text { each phase in the process planning of the hybrid process } \\
\text { is the essence of this work. The genetic algorithm has } \\
\text { been implemented in this study to minimize the } \\
\text { inspection time, besides other optimization models. The } \\
\text { setup designed for hybrid additive-subtractive- } \\
\text { inspection process has also been referred to in this work. }\end{array}$ \\
\hline
\end{tabular}
machining.

name, get face type, get face loop, get face edges, get face vertices, and get face direction.

3.3. Automatic Slicing Part to Subpart. The automated hybrid additive, subtractive, and inspection cannot be achieved without the automatic slicing of a part to a subpart. In this study, automatic slicing of a part to a subpart was achieved by dividing the CAD model into different CAD files using the CATVBA editor within CATIA V5. After slicing a part to a subpart, output data for every subpart was obtained in the STEP file format. In this automatic slicing, all data were divided automatically in an empty target file by running the code. The part peaks were the inputs to the slicing code. After that, the subpart area and volume parameters were calculated automatically and data were exported to an Excel 


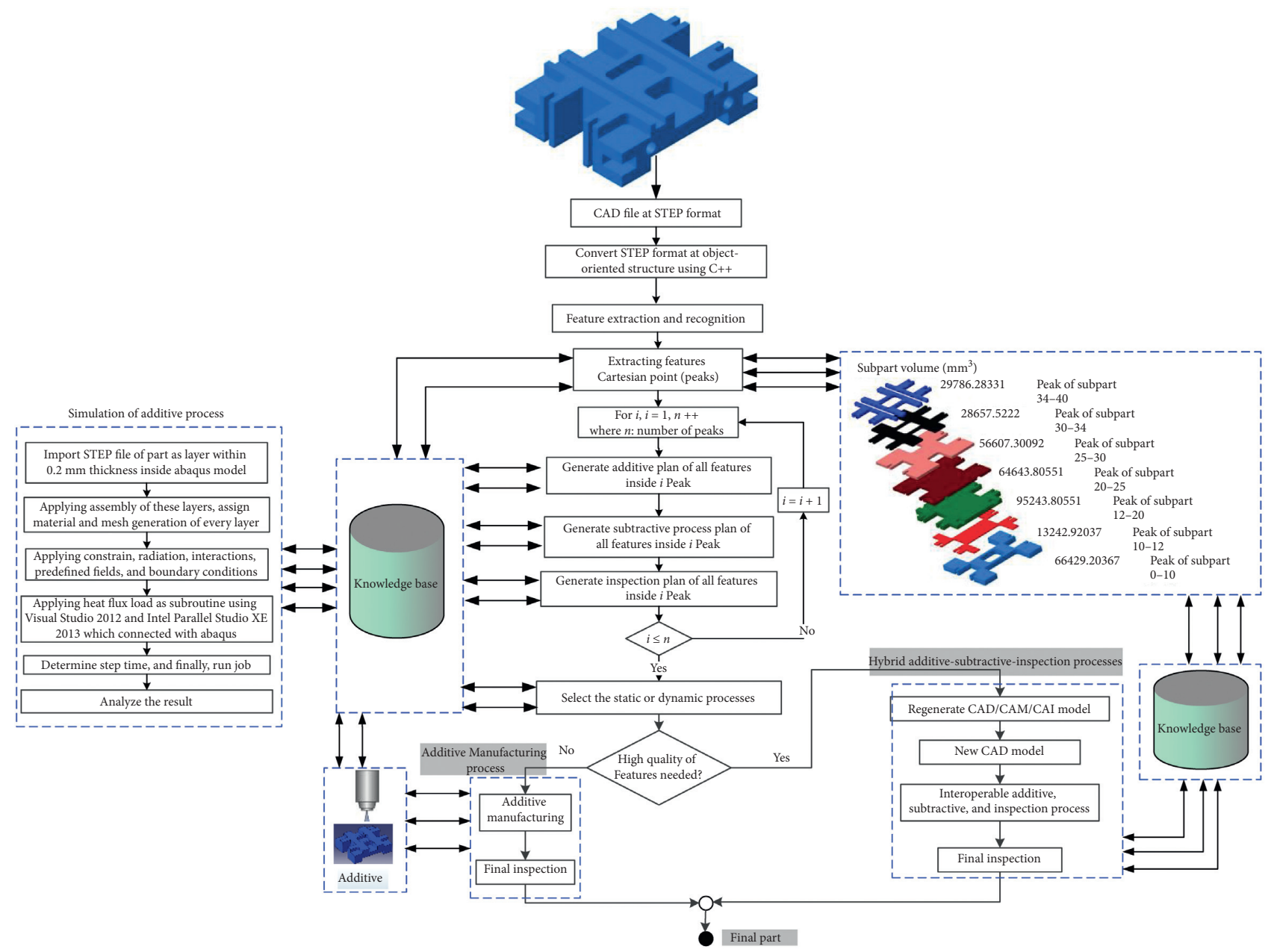

FIGURE 1: Methodology of the hybrid additive, subtractive, and inspection processes.

TABle 2: Feature recognition output [24].

\begin{tabular}{lccc}
\hline Feature ID & Feature name & Feature face IDs & Dimensions \\
\hline 1 & Pocket through & F1, F2, F3, F4 & $L=, W=, H=$ \\
2 & Hole & F5, F6 & $H=, R=$ \\
\hline
\end{tabular}

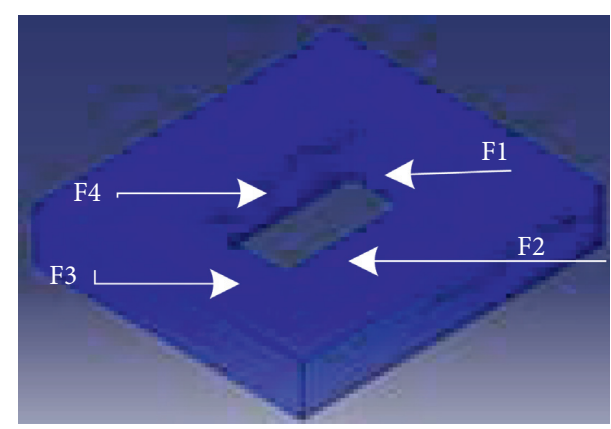

(a)

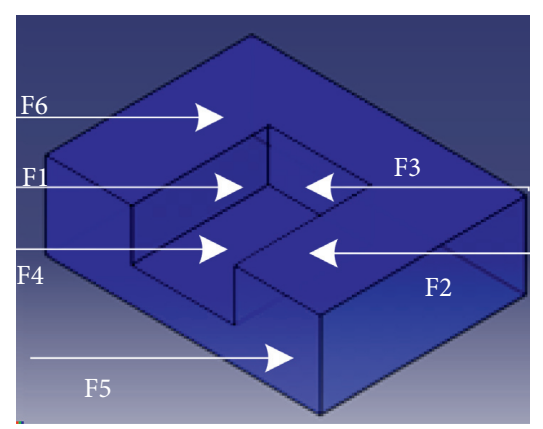

(b)

FIGURE 2: Different faces in features: (a) pocket through; (b) slot blind feature.

datasheet. The exported data were used to calculate the total additive and subtractive area and volume of the part as shown in Figure 4.
3.4. Simulation. In this work, a finite element analysis (FEA) framework (see Figure 5) has also been developed for simulating the additive process. The objective of this analysis 
TABLE 3: Inspection data extracted for the slot blind feature.

\begin{tabular}{lcccc}
\hline Feature ID & Feature name & Feature face IDs & Block face IDs & Dimensions \\
\hline 1 & Slot blind & F1, F2, F3, F4 & F5, F6 & Length = F3-F5, width = F1-F2, height = F4-F6 \\
\hline
\end{tabular}

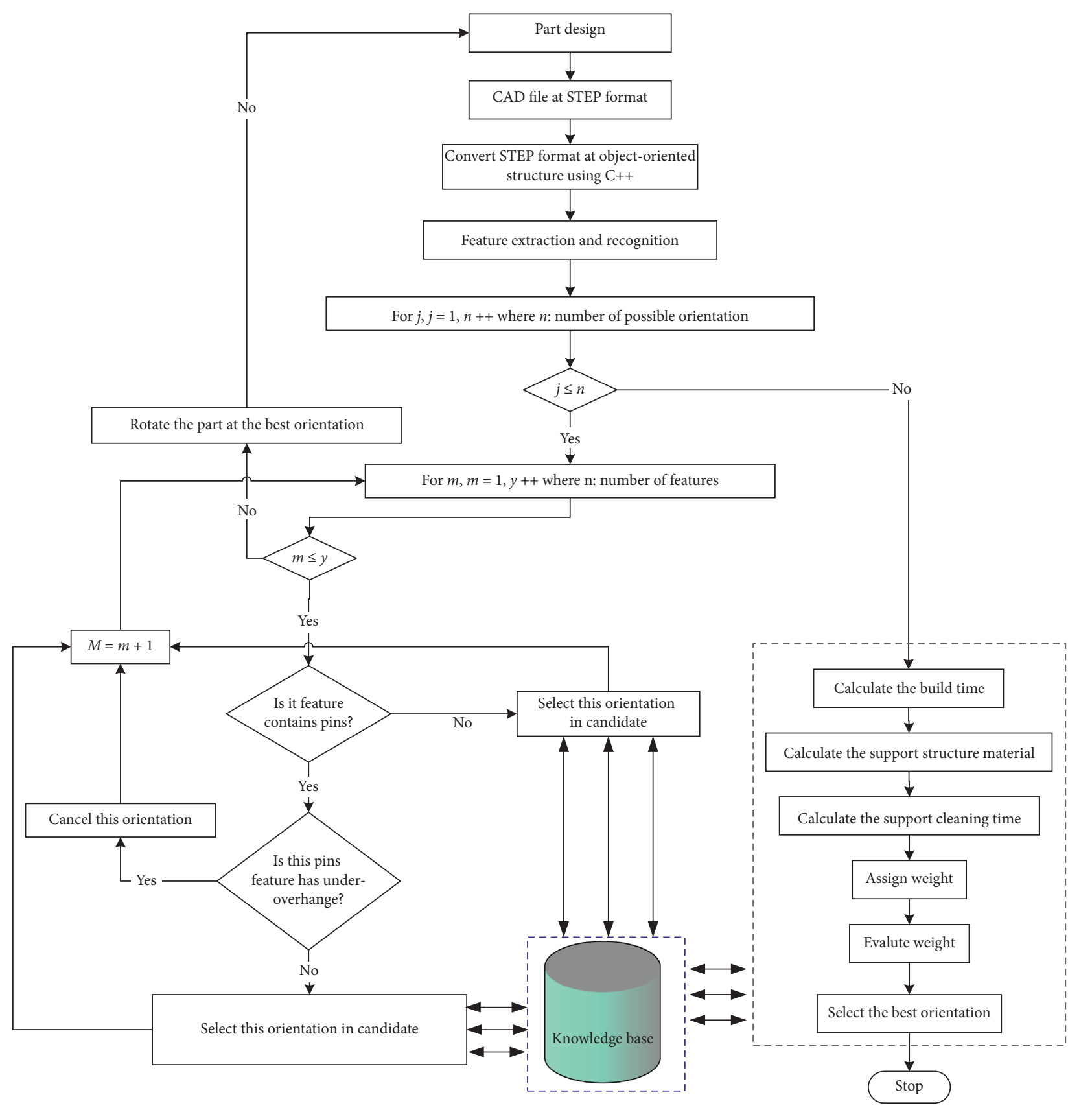

Figure 3: Part orientation.

was to arrive at the constraints for process planning. The FEA approach in this work was established similar to the scheme and mathematical models reported in [27]. This analysis was subdivided across two phases. The thermal analysis, which solves the heat equations, was carried out to assess the temperature field. The resulting temperature field was then used in the mechanical analysis to determine von Mises stress and component deformation.
The additive system employed in the current investigation was equipped with two extruders, which could be heated up to $600^{\circ} \mathrm{C}$, and a nozzle of $0.2 \mathrm{~mm}$ of diameter was used. The bed temperature could reach up to $100^{\circ} \mathrm{C}$. The different nozzle and bed temperatures, part orientations, extruder velocities, and layer thicknesses were applied to study the stress and deformations. The conditions were then identified to produce the most accurate part using additive 


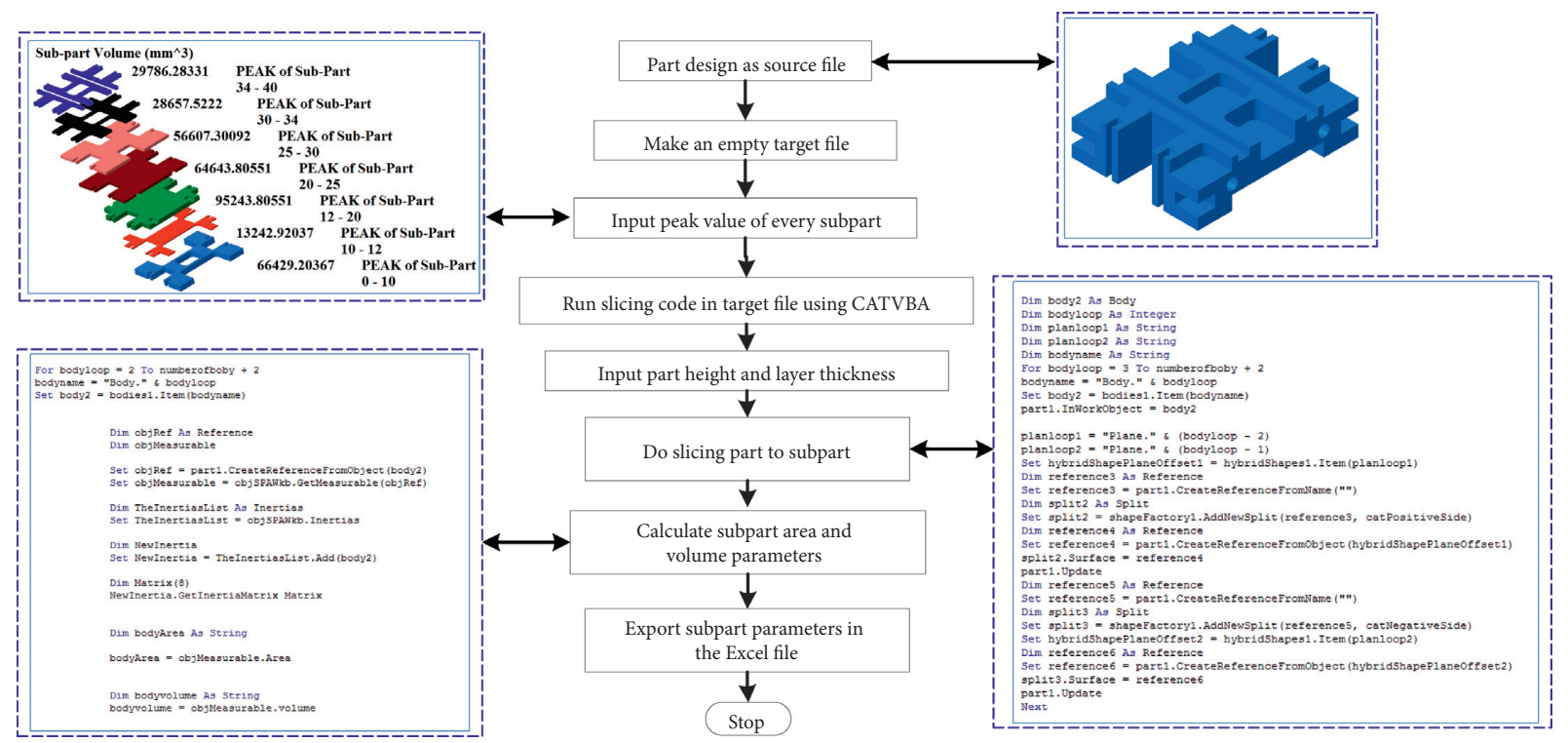

FIgURE 4: Automatic slicing of a part to a subpart [24].

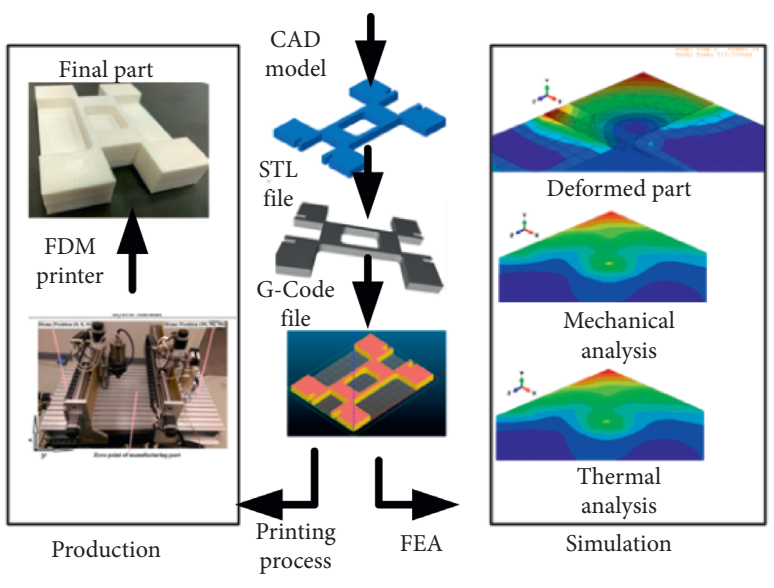

Figure 5: Schematic diagram of FEA.

manufacturing. This analysis also provided the regions (such as areas with high distortion) which could be prioritized for machining using the subtractive process. The FEA results were also utilized to define the sampling strategy required for inspection. For example, the highly deformed regions needed a higher number of points as compared to areas with low distortion.

3.5. Process Plan of Additive Operations. AM process-planning steps as shown in Figure 6 can be interpreted as the layer-based manufacturing approach, which comprises of the resource requirements including time and travel distance. These aspects comprise the number of layers, shape and size, single or multiple contours in a slice, support material, functionality, accuracy, and surface characteristics [21]. AM process steps are evenly critical and possess a significant effect on the attributes of the produced part.

3.6. Process Plan of Subtractive Operations. The subtractive process plan consists of the machining data of the designed

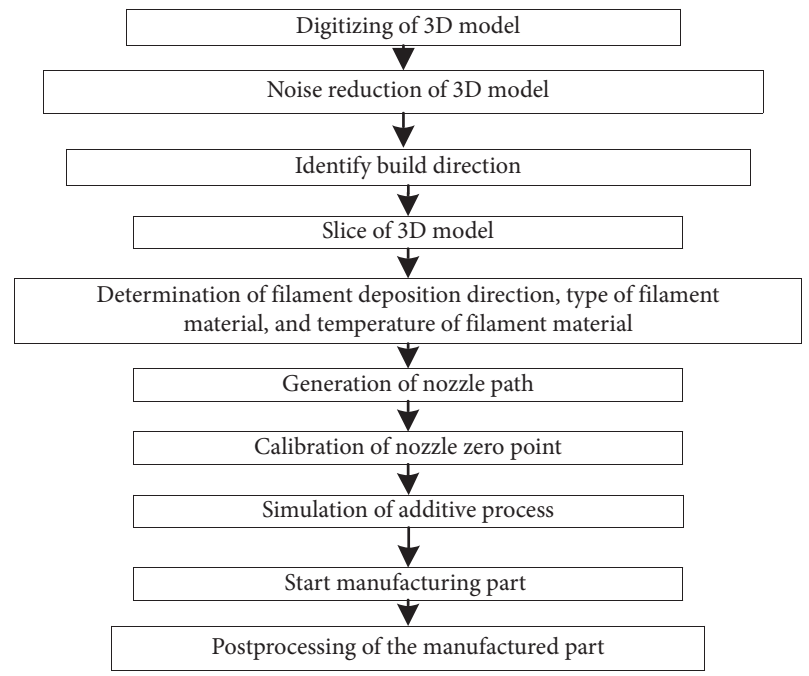

Figure 6: Additive process plan steps.

part such as sequence of machining, type of operation, machine type, cutting tool, tool approach, and the volume of material removed for each extracted feature as shown in Table 4.

3.7. Process Plan of Inspection Operations. The inspection planning can be summarized in Table 5. The different attributes of the process plan table can be described as follows:

(1) Face identification (ID) number, it determines ID of the face in the feature extraction and recognition output.

(2) ID of the inspection operation, it depicts the kind of GD\&T such as flatness, parallelism, and perpendicularity.

(3) Tolerance value, it permits designers to establish tolerance limits for the different part characteristics 
TABLE 4: Subtractive process plan.

\begin{tabular}{lcccccccc}
\hline Feature & Feature & Face & Feature & Feature & Feature & Machine & Cutting & Machine \\
ID & name & IDs & dimension & volume & location & operation & tool & tool
\end{tabular}

TABLE 5: Inspection plan table.

\begin{tabular}{|c|c|c|c|c|c|c|c|c|}
\hline $\begin{array}{l}\text { Face } \\
\text { ID }\end{array}$ & $\begin{array}{c}\text { ID of } \\
\text { inspection } \\
\text { operation }\end{array}$ & $\begin{array}{l}\text { Tolerance } \\
\text { value }\end{array}$ & $\begin{array}{l}\text { Tool } \\
\text { used }\end{array}$ & $\begin{array}{l}\text { Datum } \\
\text { face ID }\end{array}$ & $\begin{array}{l}\text { Orientation of } \\
\text { part }\end{array}$ & $\begin{array}{l}\text { No. of touch } \\
\text { points }\end{array}$ & $\begin{array}{l}\text { Coordinates of touch } \\
\text { points }\end{array}$ & $\begin{array}{c}\text { Geometric } \\
\text { inspection boundary }\end{array}$ \\
\hline 1 & GD\&T & $\begin{array}{l}\text { Tolerance } \\
\text { value }\end{array}$ & $\begin{array}{l}\text { Touch- } \\
\text { trigger probe }\end{array}$ & $\begin{array}{l}\text { Face } \\
\text { ID }\end{array}$ & Setup no. & $n$ & $\begin{array}{c}\left(U_{i}, V_{i}, W_{i}\right) \\
- \\
\left(U_{i+1}, V_{i+1}, W_{i+1}\right) \\
\left(U_{i+2}, V_{i+2}, V_{i+2}\right) \\
\cdot \\
\cdot \\
\left(U_{n}, V_{n}, V_{n}\right) \\
\end{array}$ & $\begin{array}{l}\left(X_{1}, Y_{1}, Z_{1}\right)- \\
\left(X_{2}, Y_{2}, Z_{2}\right)- \\
\left(X_{3}, Y_{3}, Z_{3}\right)- \\
\left(X_{4}, Y_{4}, Z_{4}\right)-\end{array}$ \\
\hline
\end{tabular}

after identifying its function and correlation to mating parts.

(4) Tool employed, it identifies the tools (its type, geometry, etc.), such as contact systems, noncontact techniques, horizontal probe, vertical probe, and star probe, employed for inspection. The choice of the inspection sensor for data acquisition is critical for the entire hybrid process, both in terms of measurement accuracy and time. Certainly, the contact systems, such as the touch-trigger probe is needed when inspection accuracy is favored and time is not a constraint [28]. The scanning touch probe also constitutes a contact inspection system, but it is quite fast and comparatively less accurate than a touchtrigger probe. Similarly, the noncontact systems, namely, laser scanners are preferred when accuracy can be compromised for lesser measurement time. Therefore, this step selects the most appropriate tool to prevent any damage to the part or the probe as well as satisfying the inspection requirements. Moreover, this selection is based on the location, depth, dimensions, measurement cost, orientation, and accessibility of the features.

(5) Datum (reference) faces, they represent the reference points, lines, planes, and axis. The coordinate system and the part origin is generated using these reference features.

(6) Part orientation, it represents the appropriate orientation (which covers a maximum number of features) of the prismatic part, and the setup number is identified in the table.

(7) Number of touch point, it identifies the number of points required to measure the given feature. In this work, stratified and adaptive sampling techniques have been utilized. The stratified sampling is a technique in which the complete set of points is split into subsets (also called strata) [29, 30]. The adaptive sampling demonstrates that regions with higher deformations will receive more points and regions with lower deformation or distortion should receive fewer points [31]. From the FEA, it was found that there were more distortion in the regions near the edges, and they acquired more points than in the middle regions.

(8) Touch point, it provides the coordinate of the probing point. Each boundary of the rectangular face was defined by its boundary corner and using coordinates $(x, y$, and $z)$ in the extraction module. These coordinates were utilized as input for the algorithm [22].

(9) Geometric inspection boundary-It shows the boundary of the testing face.

\section{Optimization of CAPP}

This step aimed to reduce the manufacturing time and hence the fabrication cost of the part produced using HM. To optimize the HM, the mathematical models were employed to obtain the most suitable part orientation as well as minimize the additive and subtractive times. The inspection time was optimized through the minimization of the probe measurement path using GA.

4.1. Part Orientation. The optimal orientation can enhance part quality, minimize production time, and lessen support requirements for building the part. An appropriate part orientation for lesser support volume increases the building height and accordingly decreases the fabrication time. It suggests part orientation has to be optimized to minimize support volume as well as manufacturing time. Therefore, the optimal part setup is very critical to an efficient and effective CAPP for HM. There are several parameters such as machine parameters, part geometry, part height, layer thickness, and support volume, which control the part orientation. The primary operations to achieve the optimal orientation are described as follows:

Operation 1: obtain the geometry and topology items for the designed object model from STEP file format and extract topology entities in each basic face and determine its type. 
Operation 2: calculate the GD\&T (the first objective value) using the following model:

$$
\begin{aligned}
& w_{1 j}= \begin{cases}0 & \theta_{j}=\left\{0^{\circ}, 90^{\circ}, 180^{\circ}\right\}, \\
-\cos \left(\frac{\theta}{2}\right) & \text { otherwise, }\end{cases} \\
& w_{2 j}= \begin{cases}0 & \text { no support, } \\
-0.3 & \text { need support, }\end{cases} \\
& w_{2 j}= \begin{cases}0 & \text { no overcure, } \\
-0.2 & \text { need overcure, }\end{cases}
\end{aligned}
$$

$$
W_{j}= \begin{cases}1+w_{1 j}+w_{2 j}+w_{3 j} & \theta_{j}=\left\{0^{\circ}, 90^{\circ}, 180^{\circ}\right\}, \\ w_{1 j}+w_{2 j}+w_{3 j} & \left.\theta_{j}=\right] 0^{\circ}, 90^{\circ}[U] 90^{\circ}, 180^{\circ}[, \\ -1+w_{1 j} & w_{1 j} \neq w_{2 j} \neq w_{3 j} \neq 0,\end{cases}
$$

$$
\begin{gathered}
Q_{i}=\sum_{j=1}^{n} N_{i j} W_{j}, \\
N_{j}=\frac{n_{\text {Face }} * A_{j}}{A_{\text {Total }}} .
\end{gathered}
$$

Operation 3: if $\operatorname{Max}_{i}=\{\overline{\mathrm{Q}}\}, \overline{\mathrm{Q}}$ is a set of equal maximum $Q_{i}$, the following should be done:

(a) Calculate building time and support volume

(b) Otherwise, go to Step 4

Operation 4: select $\operatorname{Max} Q_{i}$

Operation 5: stop

where $A_{j}$ represents the total face area for different faces in part orientation $i, N_{j}$ represents the relative number, which can be calculated by dividing the area of the type ( $j$ ) divided by the summation of all types, and $W_{j}$ represents the weight assigned to each type depending on its angle.

The goal of this part orientation model was the maximization of horizontal and perpendicular faces in the $z$-axis (build direction), maximization of base surface area as well as minimization of angular/inclined surfaces, overhanging area, and trapped volume. There can also be parts, where the same value of max $Q$ could be obtained for more than one orientation. Therefore, to select the best orientation, additive time was also be computed for these orientations as shown in Section 4.1.1.

4.1.1. Additive Time. The time of AM is an important factor, especially when different part orientations are available. The build time was calculated for different orientations to select the optimal one. The minimum build time indicates a minimum number of slices and a minimum volumetric error. The volumetric error is the volumetric difference between the CAD model and the AM part. Magic 18 software was used to generate the support structure of the part, and that was exported as an STL file [21]. Subsequently, the area and volume were computed.

The build time depends on machine parameters, part geometry, part height, layer thickness, and the amount of support volume needed for building the part. Therefore, the build time was opted as an output variable in each orientation of the part. The total build time was calculated by taking the summation of the time needed to cover the part geometry $\left(T_{\text {geometry }}\right)$, the time needed to build support volume ( $\left.T_{\text {support }}\right)$, and the machine time $\left(T_{\mathrm{m} / \mathrm{c}}\right)$ :

Total building time $\left(T_{\text {building }}\right)=T_{\text {geometry }}+T_{\text {support }}+T_{\mathrm{m} / \mathrm{c}}$.

$T_{\text {geometry }}$ was calculated by dividing the part volume with machine build rate and was expressed as follows:

$$
T_{\text {geometry }}=\frac{\text { Part volume }}{\text { Building rate of machine }} .
$$

$T_{\text {support }}$ was calculated by dividing the amount of support volume (which was provided by the Magic 18 software as shown in Figure 7) with the build rate of the machine:

$$
T_{\text {support }}=\frac{\text { Support volume }}{\text { Building rate of machine }} \text {. }
$$

$T_{\mathrm{m} / \mathrm{c}}$ was computed by measuring the machine setup time and postprocessing time.

4.2. Inspection Time. The reduction of inspection time can be achieved by minimizing the cycle time which primarily depends on the inspection probe path. A GA-based approach was developed to attain the best measurement path for the given part. The GA was employed because it has shown in the past its relevance and benefits in addressing path-planning problems. There are many reasons for its superior performance in comparison with other metaheuristics. The GA is swift, easy to execute, and cost-effective in terms of computational resources. It yields the most stable results and can be used to solve challenging problems in a limited timeframe. It is far better than any other method considering the size of the search area. GA generally performs well because of its parallel search features, where several solutions are merged dynamically until an effective solution is obtained. Since the GA deploys the randombased search algorithms to analyze most of the state space. Therefore, the quality of the acquired solution gets enhanced. Besides, GA's fewer parameter interactions with just three parameters (population size, crossover probability, and mutation probability) make it simpler, easier to implement, and avoid numerous local optimal solutions in the parameter domain to provide quality solutions. The subsequent section explains the implementation of the GA in this work. The touch points (or measurement points) were specified based on the objective function to ensure the shortest path between two measuring features, as shown in Figure 8 . 


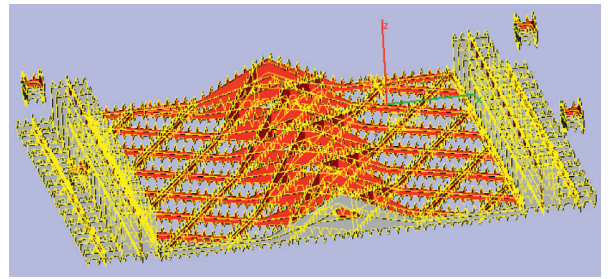

Figure 7: Support volume generated by Magic 18 software [24].

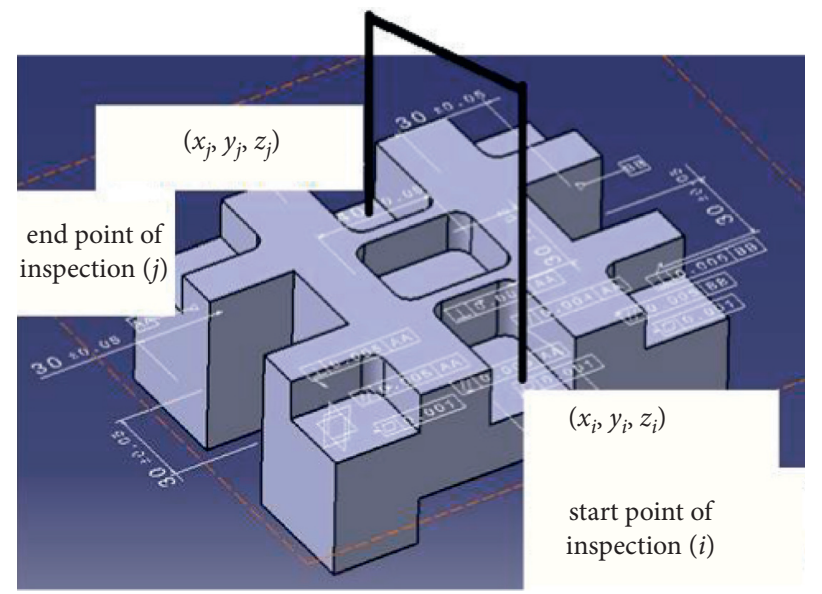

Figure 8: Probe path planning based on an objective function.

Step 1: random solutions (chromosomes)

Initially, the measuring features were grouped based on a generated random solution (chromosome). Subsequently, the touch-point coordinates (input) of the sequenced features were rearranged according to the objective function for obtaining the shortest path between two sequenced features as shown in Figure 9.

Step 2: computation of the fitness function for each chromosome

The fitness function can be defined as the total shortest path between two sequenced features. The objective function can be described as

$$
\sum_{k=1}^{P}\left[\operatorname{Min}_{i=R}^{R}\left(\operatorname{Min}_{j=1}^{m=1} \sqrt{\left(x_{R}-x_{j}\right)^{2}+\left(y_{R}-y_{j}\right)^{2}+\left(z_{R}-z_{j}\right)^{2}}\right)\right] \text {, }
$$

where $i$ is the first touch point of the first sequenced feature, $j$ is the first touch point of the next sequenced feature, $n$ is the number of touch point coordinates of the last sequenced feature, $m$ is the number of touch point coordinates of the next sequenced feature, and $P$ is the number of sequenced features.

\section{Step 3: crossover and mutation}

Single-point and two-point crossover operators as shown in Figure 10 were used. For the mutation operator, the random swap mutation operator was utilized.

Step 4: stopping criterion
The stopping criterion employed in this study was the maximum number of iterations. This stopping criterion was adopted because it helped to control the processing time as well as eliminate any bias.

\section{Case Study}

The proposed method can successfully be applied to any prismatic part. The established approach had in fact been implemented for many parts with prismatic features to validate its performance. However, to limit the length of the manuscript, the paper contains only one case study as shown in Figure 11 to depict the working and the findings of the proposed method. The 3D solid model was designed in CATIA V5, and the GD\&T data were obtained from the STEP AP 203 file utilizing an object-oriented technique. Seventy-two faces were obtained from the geometric information file, including their loops, edges, vertices, face direction, face type, and face area. Twelve manufacturing features were obtained and recognized, inclusive of their dimensions. The feature ID, feature name, feature face IDs, and feature dimensions are indexed in the output extraction table (Table 6). Table 7 represents the subtractive process plan obtained after feature extraction and recognition.

5.1. Part Orientation. A comparison between the different orientations was examined depending on the GD\&T and building time needed for the entire part [24]. Figure 12 represents the hybrid setup consisting of additive, subtractive, and inspection centers. 


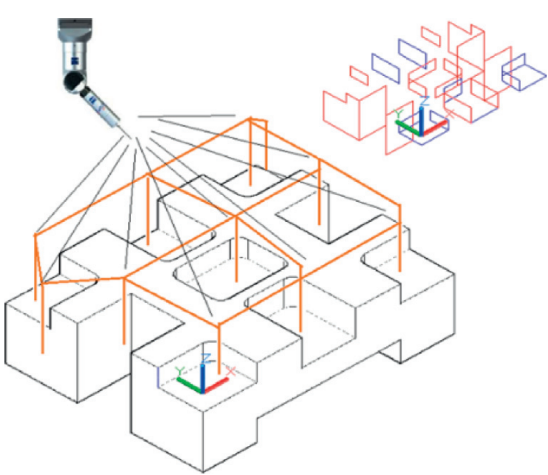

(a)

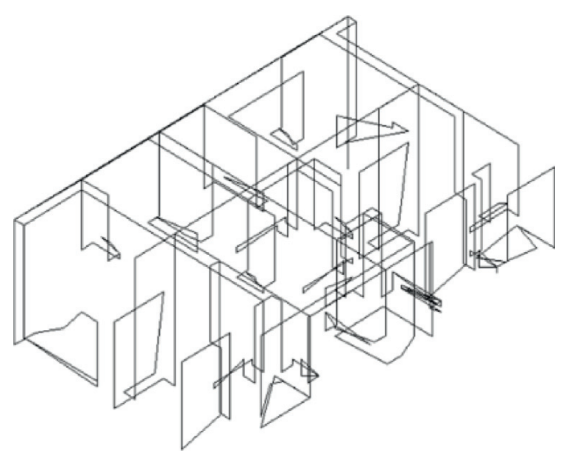

(b)

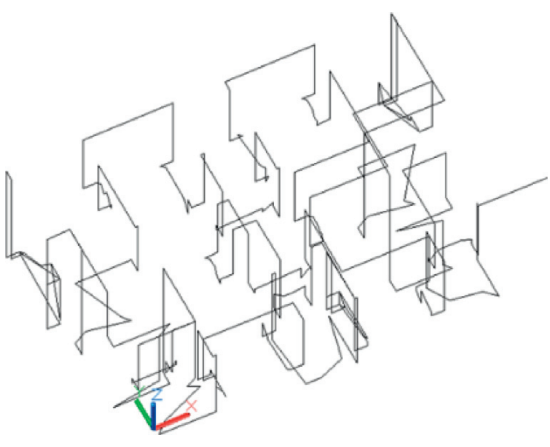

(c)

Figure 9: (a) Measured part; (b) measurement path before GA; (c) measurement path after GA.

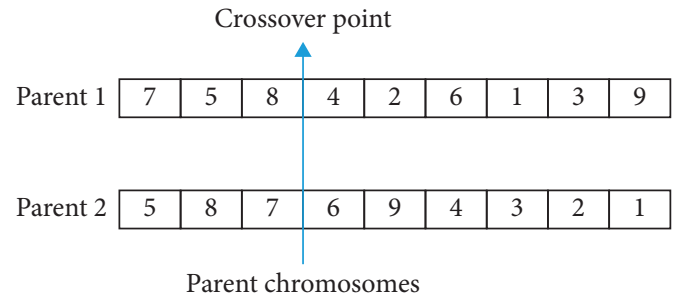

Parent chromosomes

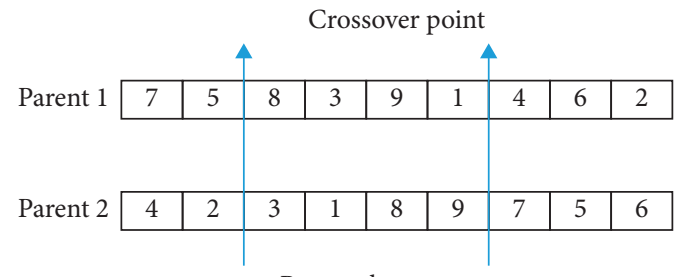

Parent chromosomes

\begin{tabular}{|l|l|l|l|l|l|l|l|l|}
\hline 7 & 5 & 8 & 4 & 2 & 6 & 1 & 3 & 9 \\
\hline
\end{tabular}

Initial chromosome

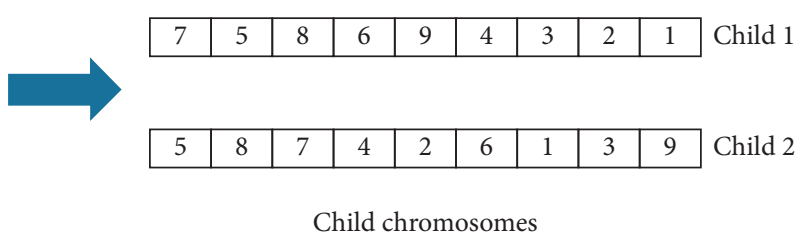

(a)

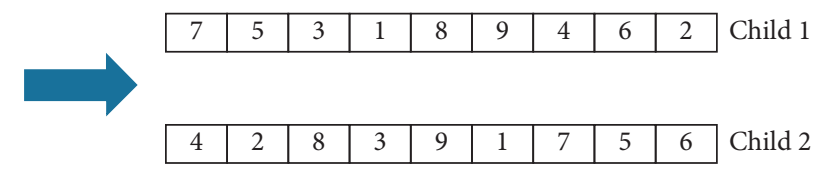

Child chromosomes

(b)

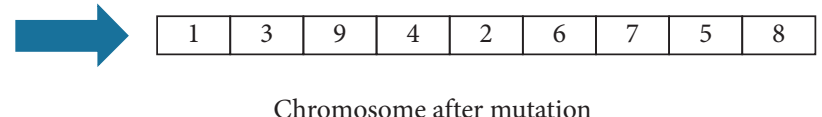

(c)

Figure 10: Crossover and mutation operators: (a) single-point crossover. (b) Two-point crossover. (c) Swap mutation.

There were four possible orientations of the part. These were $(+x,-x)$ orientations and $(+y,-y)$ orientations as shown in Figure 13.

An overhanging surface is a type of prismatic geometric feature that warps easily if the inclination angle is smaller. It results in a staircase volume, which causes a dimensional error and poor surface roughness. The resulting data as shown in Table 8 represent the total face area $\left(A_{j}\right)$ for different faces in part orientation $(i)$. To determine the best orientation, the relative number $\left(N_{j}\right)$, which is the area of type $(j)$ divided by the summation of all types, was calculated. Next, the weight $\left(W_{j}\right)$ was assigned to each type depending on its angle. Next, $Q_{i}$ was calculated for each type by multiplying the relative number $\left(N_{j}\right)$ of the face $(j)$ with its weight. Finally, the $Q_{i}$ for each type was added up to get the final rating for the given orientation. This final rating for each orientation was then compared with the ratings obtained for other orientation to select the best orientation of the part.

It is obvious from the above table that orientation 2 had the maximum $Q_{i}$ value, based on the output of the GD\&T objective function.

5.2. Additive Time. The constant factors used in the model are shown in Table 9.

The additive time for different orientation was also computed to further examine the best orientation. After computing the additive time, orientation 2 was found to have the least building time as shown in Table 10. 


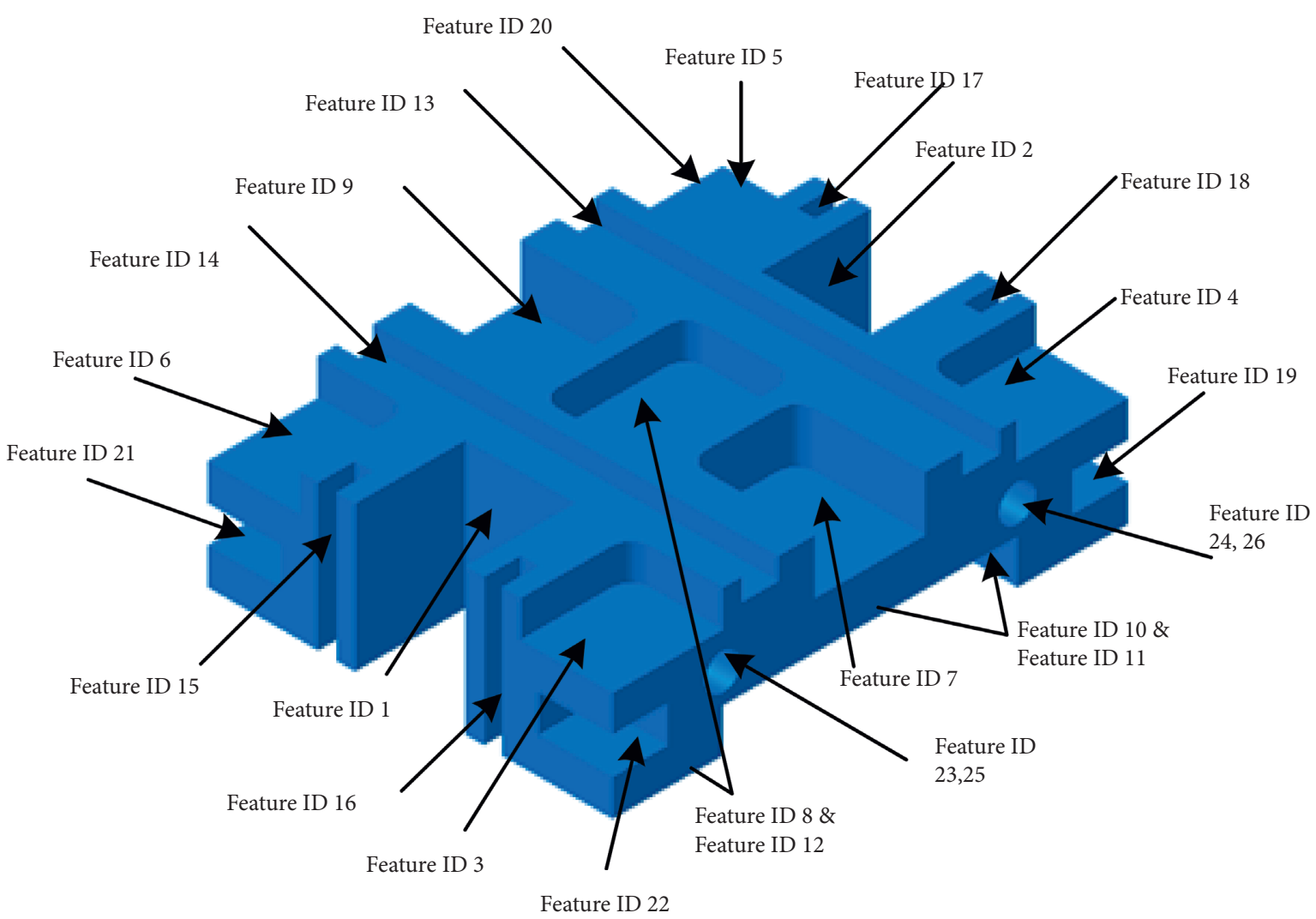

Figure 11: Test part (solid body) with feature IDs.

TABLE 6: Feature extraction and recognition.

\begin{tabular}{|c|c|c|c|c|}
\hline Feature ID & Feature name & Face IDs & Feature dimension & Feature peak \\
\hline 1 & Slot through & $2,1,3$ & Height: 40 , width: 30 , length: 30 & $0-40$ \\
\hline 2 & Slot through & $5,6,4$ & Height: 40 , width: 30 , length: 30 & $0-40$ \\
\hline 3 & STEP blind round corner & $9,7,10,7$ & Length: 30 , width: 25 , height: 10 , radius: 5 & $30-40$ \\
\hline 4 & STEP blind round corner & $13,12,14,12$ & Length: 30 , width: 25 , height: 10 , radius: 5 & $30-40$ \\
\hline 5 & STEP blind round corner & $16,17,18,17$ & Length: 30 , width: 25 , height: 10 , radius: 5 & $30-40$ \\
\hline 6 & STEP blind round corner & $20,19,22,19$ & Length: 30 , width: 25 , height: 10 , radius: 5 & $30-40$ \\
\hline 7 & Slot blind round corner & $27,23,24,26,24,25$ & Length: 35 , width: 30 , height: 15 , radius: 5 & $25-40$ \\
\hline 8 & Pocket blind round corner & $35,37,34,33,30,31,32,29,36$ & Length: 40 , width: 30 , height: 10 , radius: 5 & $30-40$ \\
\hline 9 & Slot blind round corner & $42,40,43,41,43,38$ & Length: 35 , width: 30 , height: 15 , radius: 5 & $25-40$ \\
\hline 10 & Slot blind round corner & $48,44,45,47,45,46$ & Length: 35 , width: 80 , height: 12 , radius: 5 & $0-12$ \\
\hline 11 & Slot blind round corner & $54,52,51,53,51,50$ & Length: 35 , width: 80 , height: 12 , radius: 5 & $0-12$ \\
\hline 12 & Pocket blind round corner & $62,64,61,60,57,58,59,56,63$ & Length: 40 , width: 30 , height: 10 , radius: 5 & $0-10$ \\
\hline 13 & Slot through & $67,68,66$ & Length: 110 width: 10 height: 6 & $34-40$ \\
\hline 14 & Slot through & $70,69,71$ & Length: 110 , width: 10 , height: 6 & $34-40$ \\
\hline 15 & Slot through & $76,77,75$ & Length: 40 , width: 5 , height: 10 & $0-40$ \\
\hline 16 & Slot through & $79,80,78$ & Length: 40 width: 5 height: 10 & $0-40$ \\
\hline 17 & Slot through & $86,85,87$ & Length: 40 , width: 5 , height: 10 & $0-40$ \\
\hline 18 & Slot through & $89,88,90$ & Length: 40 , width: 5 , height: 10 & $0-40$ \\
\hline 19 & Slot blind & $94,95,93,96$ & Length: 20 , width: 10 , height: 15 & $10-20$ \\
\hline 20 & Slot blind & $98,99,97,100$ & Length: 15 , width: 10 , height: 20 & $10-20$ \\
\hline 21 & Slot blind & $104,105,103,106$ & Length: 20 , width: 10 , height: 15 & $10-20$ \\
\hline 22 & Slot blind & $108,109,107,110$ & Length: 20 , width: 10 , height: 15 & $10-20$ \\
\hline 23 & Hole blind & $112,113,114$ & Radius: 5, height: 15 & $15-25$ \\
\hline 24 & Hole blind & $116,115,117$ & Radius: 5, height: 15 & $15-25$ \\
\hline 25 & Hole blind & $120,119,121$ & Radius: 5, height: 15 & $15-25$ \\
\hline 26 & Hole blind & $122,123,124$ & Radius: 5, height: 15 & $15-25$ \\
\hline
\end{tabular}




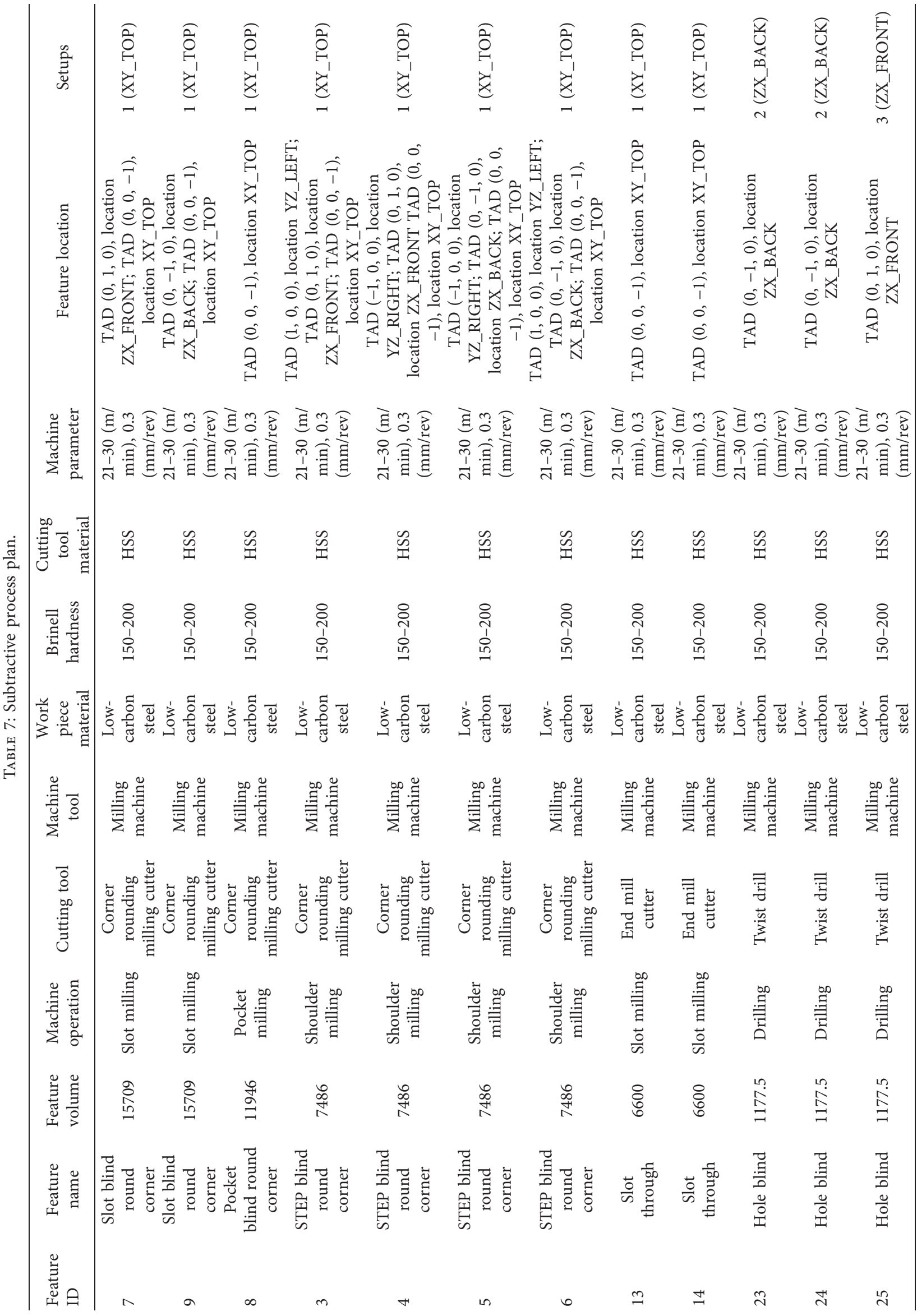




\begin{tabular}{|c|c|c|c|c|c|c|c|c|}
\hline 胥 & 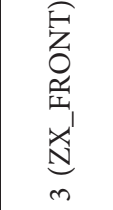 & 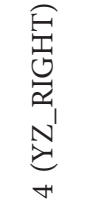 & 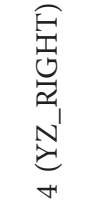 & 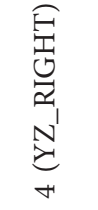 & 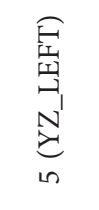 & 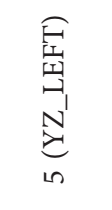 & 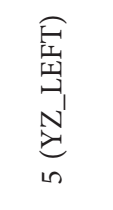 & 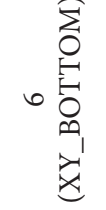 \\
\hline 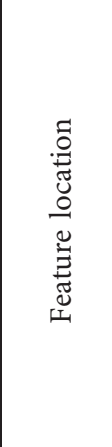 & 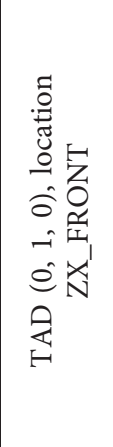 & 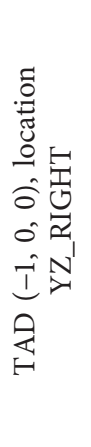 & 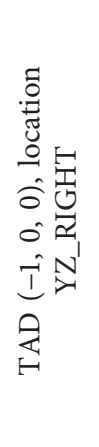 & 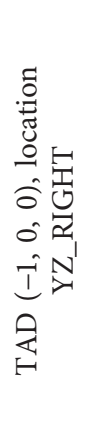 & 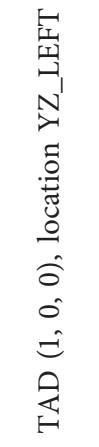 & 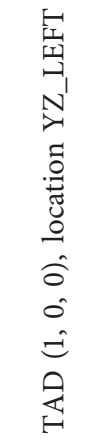 & 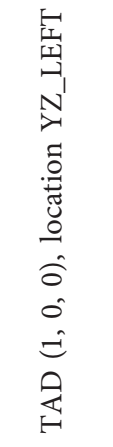 & 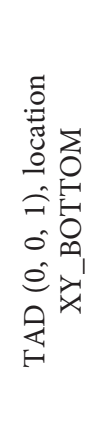 \\
\hline 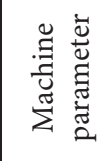 & \multicolumn{8}{|c|}{ 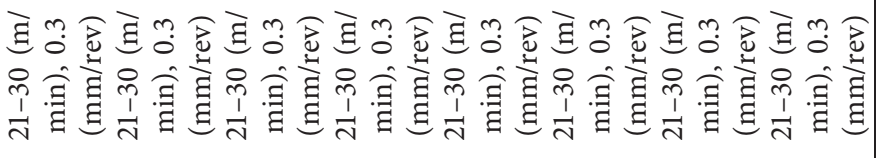 } \\
\hline 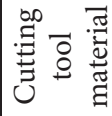 & 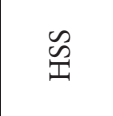 & 焉 & $\begin{array}{l}n \\
\text { 出 }\end{array}$ & 岂 & $\begin{array}{l}n \\
\text { 至 }\end{array}$ & $\begin{array}{l}\mathscr{A} \\
\text { 出 }\end{array}$ & $\begin{array}{l}\mathscr{N} \\
\tilde{M}\end{array}$ & $\begin{array}{l}\mathscr{A} \\
\tilde{M}\end{array}$ \\
\hline 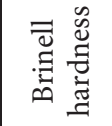 & 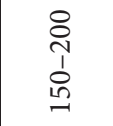 & $\begin{array}{l}\stackrel{0}{0} \\
\text { 1ิ } \\
10 \\
\end{array}$ & $\begin{array}{l}8 \\
\stackrel{1}{1} \\
\stackrel{1}{0} \\
\end{array}$ & 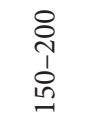 & $\begin{array}{l}8 \\
\stackrel{1}{1} \\
1 \\
10 \\
\end{array}$ & $\begin{array}{l}8 \\
\stackrel{1}{1} \\
\stackrel{1}{0} \\
\end{array}$ & \begin{tabular}{l}
8 \\
\multirow{1}{1}{} \\
1 \\
1 \\
1
\end{tabular} & $\begin{array}{l}8 \\
\text { ì } \\
\stackrel{1}{0} \\
1\end{array}$ \\
\hline 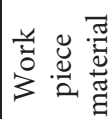 & 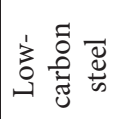 & 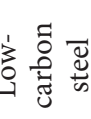 & 空 & 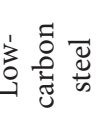 & 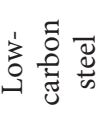 & 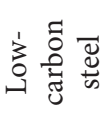 & & 客 \\
\hline $\begin{array}{l}\text { 节 } \\
\text { 旁 }\end{array}$ & 畳莺 & 咅泀 & 鸪莺 & 睴营 & 晅泀 & 晅节 & 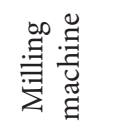 & 品节 \\
\hline 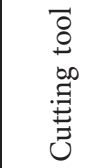 & 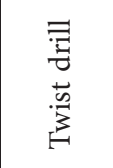 & 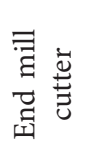 & 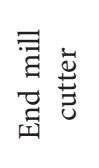 & 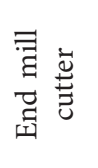 & 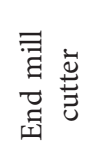 & $\begin{array}{l}\bar{\Xi} \\
\vec{\Xi} \\
\vec{\Xi} \\
\vec{\Xi}\end{array}$ & 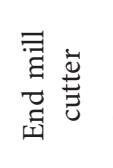 & 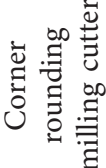 \\
\hline 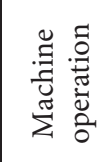 & $\begin{array}{l}\stackrel{\infty}{.} \\
\text { 音 }\end{array}$ & 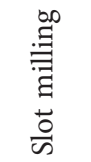 & $\begin{array}{l}\stackrel{\infty}{g} \\
\stackrel{\Xi}{\vec{\Xi}} \\
\stackrel{0}{a}\end{array}$ & 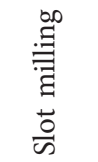 & 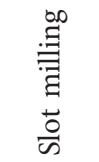 & $\begin{array}{l}\text { 号 } \\
\text { 高 } \\
\text { 总 }\end{array}$ & 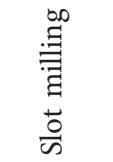 & 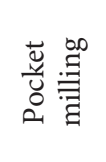 \\
\hline 莺 芩 & $\stackrel{n}{\stackrel{n}{N}}$ & : & ¿े̀ & ¿্̀ & $\begin{array}{l}8 \\
\text { o } \\
\text { d }\end{array}$ & ஓి & ঃి & $\stackrel{0}{\stackrel{1}{\Xi}}$ \\
\hline 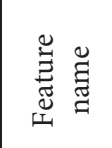 & 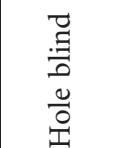 & 总 & 总 & 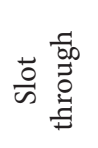 & 总总 & 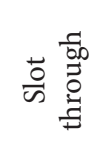 & क & 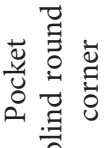 \\
\hline 苞 & 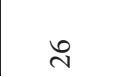 & & $\stackrel{2}{\sim}$ & $\underset{-1}{0}$ & 4 & $\approx$ & $\stackrel{\infty}{\sim}$ & $\beth$ \\
\hline
\end{tabular}




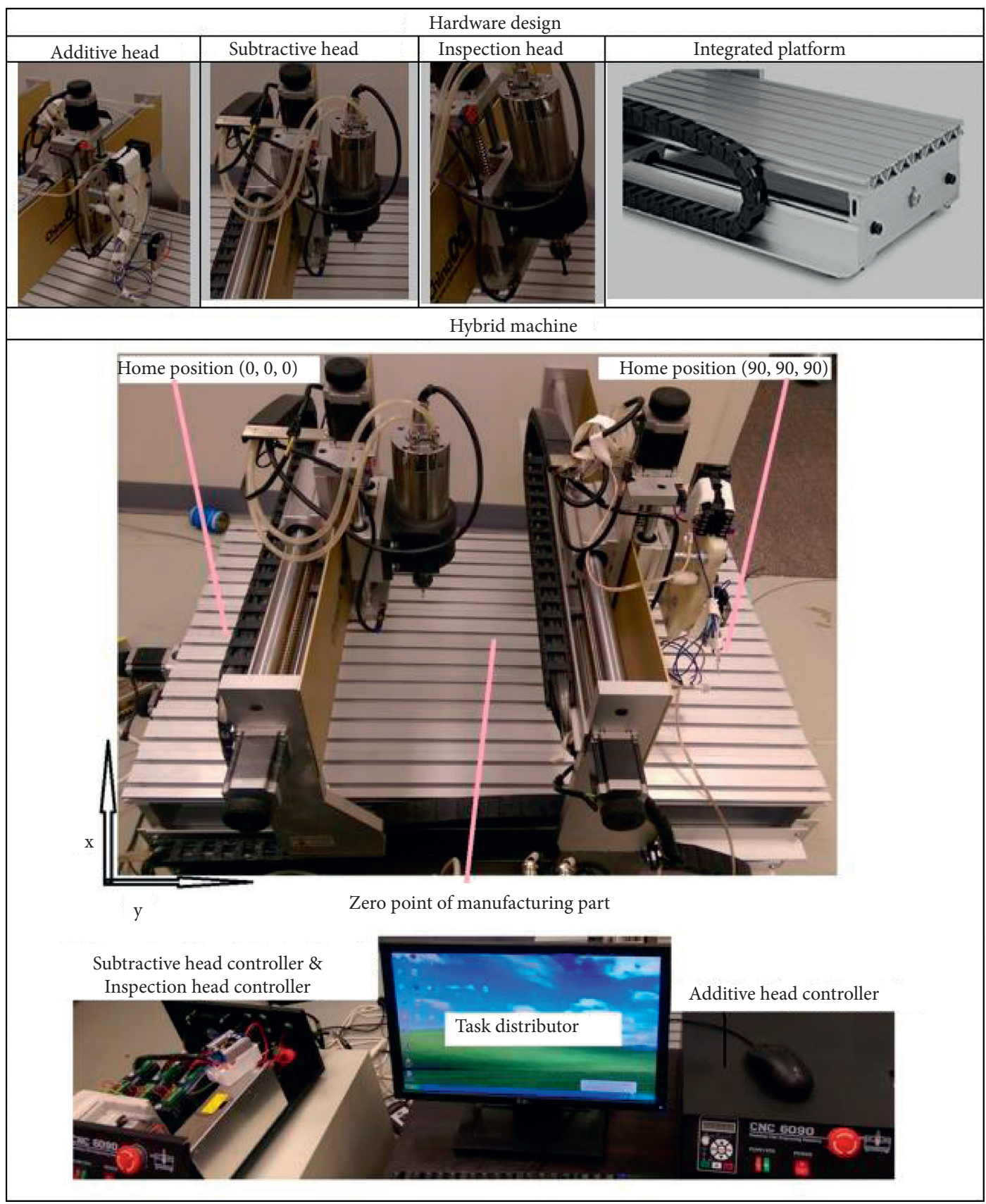

FIGURE 12: Hybrid additive, subtractive, and inspection machine setup.

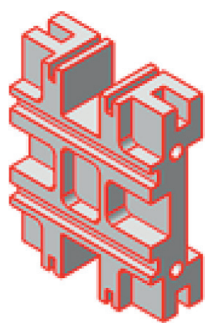

(a)

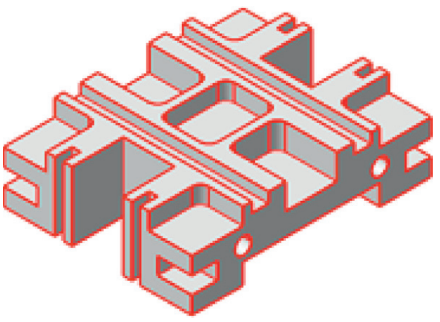

(b)

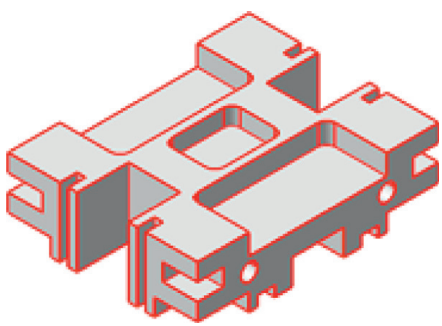

(c)

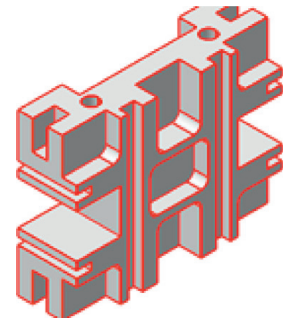

(d)

FIGURE 13: (a) Orientation no. 1; (b) orientation no. 2; (c) orientation no. 3; (d) orientation no. 4. 
TABLE 8: GD\&T objective function for orientations $1,2,3$, and 4.

\begin{tabular}{|c|c|c|c|c|c|c|c|c|c|c|c|c|c|c|}
\hline & Type & [1] & [2] & [3] & [4] & [5] & [6] & [7] & [8] & [9] & {$[10]$} & [11] & [12] & [13] \\
\hline Orient. 1 & $\begin{array}{c}Q_{i} \\
\operatorname{Sum}\left(Q_{i}\right)\end{array}$ & 14.12 & 49.70 & 18.87 & 0 & -24.78 & 0 & $\begin{array}{c}0 \\
55.655\end{array}$ & 0 & 0 & 0 & -0.77 & -1.48 & 0 \\
\hline Orient. 2 & $\begin{array}{c}Q_{i} \\
\operatorname{Sum}\left(Q_{i}\right)\end{array}$ & 40.72 & 45.96 & 6.59 & 0 & -9.37 & 0 & $\begin{array}{c}0 \\
86.56\end{array}$ & 0 & 0 & 2.07 & 0.59 & 0 & 0 \\
\hline Orient. 3 & $\begin{array}{c}Q_{i} \\
\operatorname{Sum}\left(Q_{i}\right)\end{array}$ & 20.72 & 38.80 & 6.592 & 0 & -22.24 & 0 & $\begin{array}{c}0 \\
45.38\end{array}$ & 0 & 0 & 0.47 & 1.03 & 0 & 0 \\
\hline Orient. 4 & $\begin{array}{c}Q_{i} \\
\operatorname{Sum}\left(Q_{i}\right)\end{array}$ & 23.13 & 44.24 & 3.76 & 0 & -22.91 & 0 & $\begin{array}{c}0 \\
46.915\end{array}$ & 0 & 0 & 0 & -0.207 & -1.11 & 0 \\
\hline
\end{tabular}

TABLE 9: The constant factors.

\begin{tabular}{lcc}
\hline Factor & Value & Units \\
\hline Building rate & 30 & $\mathrm{~cm}^{3} / \mathrm{h}$ \\
Batch size & 2 & $\mathrm{Parts}$ \\
Scan speed & 25 & $\mathrm{~m} / \mathrm{s}$ \\
Density & 0.9 & $\mathrm{~g} / \mathrm{cm}^{3}$ \\
Material price & 60 & $\$ / \mathrm{kg}$ \\
\hline
\end{tabular}

Table 10: Additive process plan.

\begin{tabular}{lcccc}
\hline & Orient. 1 & Orient. 2 & Orient. 3 & Orient. 4 \\
\hline Part building time $(\mathrm{h})$ & $20 \mathrm{hr} 45 \mathrm{~min}$ & $15 \mathrm{hr} 25 \mathrm{~min}$ & $15 \mathrm{hr} 59 \mathrm{~min}$ & 281160 \\
Part volume $\left(\mathrm{mm}^{3}\right)$ & 281160 & 281160 & 33890 & 281160 \\
Support volume $\left(\mathrm{mm}^{3}\right)$ & 44020 & 30260 & 0.5 & 33940 \\
Preparation time $(\mathrm{h})$ & 0.5 & 0.5 & $28 \mathrm{~min}$ & 0.5 \\
Postprocessing time $(0.10 \mathrm{~h} / \mathrm{kg})$ & $41 \mathrm{~min}$ & $26 \mathrm{~min}$ & $16 \mathrm{hr} 57 \mathrm{~min}$ & $19 \mathrm{hr} 42 \mathrm{~min}$ \\
Total building time $(\mathrm{h})$ & $22 \mathrm{hr} 6 \mathrm{~min}$ & $16 \mathrm{hr} 21 \mathrm{~min}$ & & \\
\hline
\end{tabular}

5.3. Requirements of Process Planning. The mandatory requirements of the process planning were obtained through FEA discussed in Section 3.5. The FEA was performed using the commercial software ABAQUS (Abaqus v 6.14, Dassault Systems). The Visual Studio (v 2012) and compiler (Intel Parallel Studio XE 2013) were employed to connect the subroutine with the Abaqus. The material properties were adapted to conform to a commercial acrylonitrile butadiene styrene (ABS) filament as shown in Table 11.

Figures 14(a) and 14(b) demonstrate the orientation of the part with regard to the building platform and the layers of the sliced model, respectively. The meshing strategy consisted of Hex-dominated elements with a minimum size of $0.2 \mathrm{~mm}$. This simulation involved approximately 92000 elements in total. The simulation was performed for five layers due to limited computational resources.

The simulation was performed in several conditions, involving different part orientations as well as temperatures. The lowest von Mises stress and deformation as shown in Figures 15(a) and 15(b), respectively, were obtained under following conditions: part setup, orientation 2; layer thickness, $0.2 \mathrm{~mm}$; extruder temperature, $240^{\circ} \mathrm{C}$; bed temperature, $80^{\circ} \mathrm{C}$; ambient temperature, $25^{\circ} \mathrm{C}$; extruder velocity, $20 \mathrm{~mm} / \mathrm{s}$; and nozzle diameter, $0.2 \mathrm{~mm}$. The maximum value of von Mises stress was $0.02875 \mathrm{MPa}$, and maximum deformation was $1.6 \times 10^{-5} \mathrm{~mm}$. These conditions also defined the constraints for the additive process. The additive process had to be
TABLE 11: Mechanical and thermal properties of the ABS at the ambient temperature.

\begin{tabular}{lc}
\hline Property & Value \\
\hline Density & $1040 \mathrm{~kg} / \mathrm{m}^{3}$ \\
Young's modulus & $1826 \mathrm{MPa}$ \\
Poisson's ratio & 0.32 \\
Yield stress & $25 \mathrm{MPa}$ \\
Thermal expansion coefficient & $9 \times 10^{-50} \mathrm{C}^{-1}$ \\
Specific heat & $1290 \mathrm{~J} /\left({ }^{\circ} \mathrm{C} . \mathrm{kg}\right)$ \\
Thermal conductivity & $0.15 \mathrm{~W} /\left({ }^{\circ} \mathrm{C} . \mathrm{m}\right)$ \\
Glass transition temperature & $95^{\circ} \mathrm{C}$ \\
\hline
\end{tabular}

executed in these conditions to get the best results and minimize the usage of subtractive machining. It was also found that the deformation was maximum at the edges; that is, it increased from the center of the part to its boundary. As a consequence, the sample size was optimized, where more points were assigned in regions near the edges.

5.4. Inspection Time. For the present case study, the maximum number of iterations of 2000 yielded the best result. With this maximum number of iterations, the length of the obtained probe path was $617.23 \mathrm{~mm}$. As shown in Table 12, the probe's travel distance between two features decreased with an increasing number of iterations. However, it stabilized after 2000 generations, and no additional 


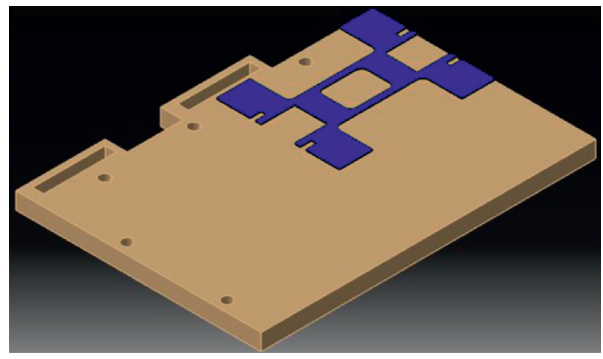

(a)

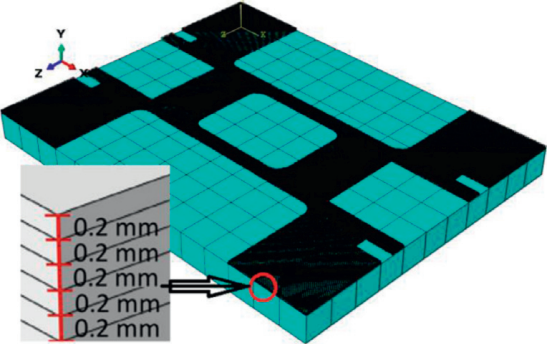

(b)

Figure 14: (a) Layer orientation; (b) meshing strategy.

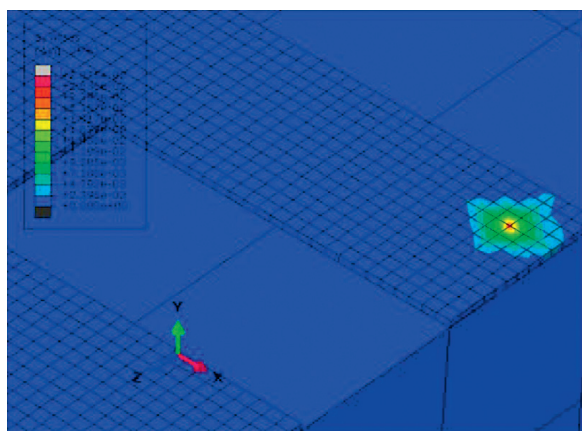

(a)

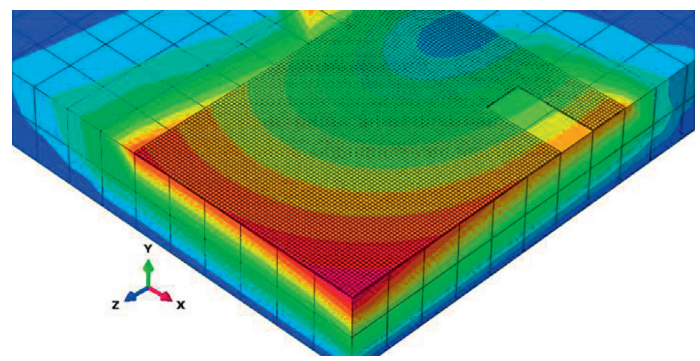

(b)

FIGURE 15: (a) Stress distribution; (b) resultant total deformation.

TABle 12: Application of the GA to determine the inspection path for a subpart.

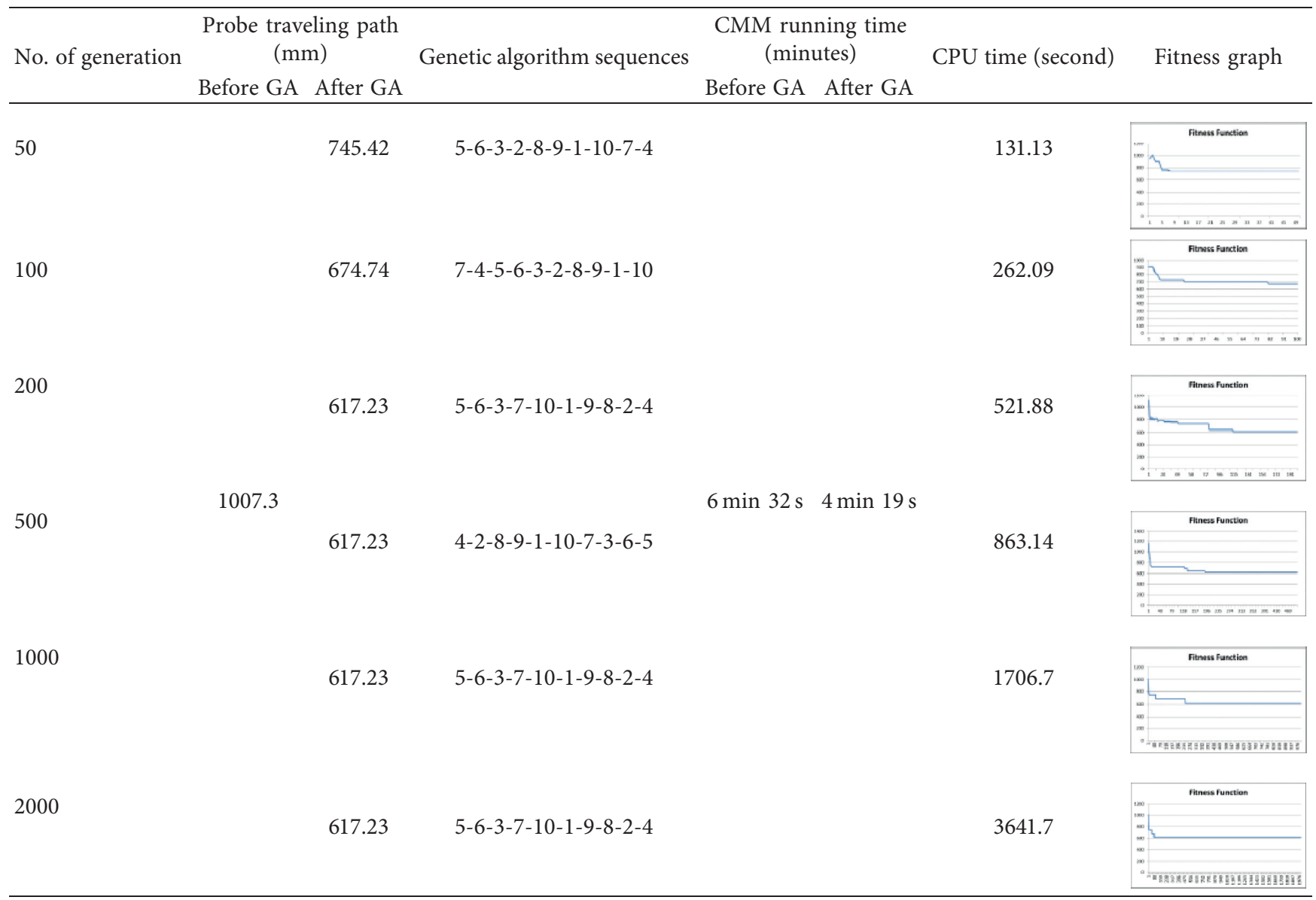


TABLE 13: All possible peaks and subparts.

\begin{tabular}{|c|c|c|c|c|c|c|c|c|c|}
\hline \multirow[b]{2}{*}{$\begin{array}{l}\text { Sequence } \\
\text { operation }\end{array}$} & \multirow[b]{2}{*}{ Subpart } & \multirow[b]{2}{*}{$\begin{array}{l}\text { Subpart } \\
\text { peak (or } \\
\text { subpart } \\
\text { peak } \\
\text { height) }\end{array}$} & \multicolumn{3}{|c|}{ Additive processes } & \multicolumn{4}{|c|}{ Subtractive processes } \\
\hline & & & $\begin{array}{l}\text { Machine } \\
\text { type }\end{array}$ & $\begin{array}{l}\text { Subpart } \\
\text { volume } \\
(\mathrm{ABS} \\
\text { filament } \\
\text { volume) } \\
\left(\mathrm{mm}^{3}\right)\end{array}$ & $\begin{array}{l}\text { Building } \\
\text { time (hr) }\end{array}$ & $\begin{array}{l}\text { Subpart and } \\
\text { subtractive } \\
\text { feature IDs }\end{array}$ & $\begin{array}{l}\text { Subtractive } \\
\text { operation }\end{array}$ & $\begin{array}{l}\text { Subtractive } \\
\text { area }\left(\mathrm{mm}^{2}\right)\end{array}$ & $\begin{array}{c}\text { Machine } \\
\text { type }\end{array}$ \\
\hline 1 & & $0-10$ & $\begin{array}{c}\text { FDM } \\
\text { machine }\end{array}$ & 66429.20 & 3.52 & $\begin{array}{l}\text { ID } 1 \text {, ID } 2 \text {, ID } \\
10, \text { ID } 11, \text { ID } \\
12 \text {, ID } 15 \text {, ID } \\
16, \text { ID } 17 \text {, ID } \\
18\end{array}$ & $\begin{array}{c}\text { Surface } \\
\text { finish }\end{array}$ & 9000 & $\begin{array}{l}\text { Milling } \\
\text { machine }\end{array}$ \\
\hline 2 & & $10-12$ & $\begin{array}{c}\text { FDM } \\
\text { machine }\end{array}$ & 13242.92 & 1.02 & $\begin{array}{l}\text { ID } 1 \text {, ID } 2, \text { ID } \\
10 \text {, ID } 11, \text { ID } \\
15 \text {, ID } 16 \text {, ID } \\
17 \text {, ID } 18 \text {, ID } \\
19, \text { ID } 20 \text {, ID } \\
21, \text { ID } 22\end{array}$ & $\begin{array}{l}\text { Surface } \\
\text { finish }\end{array}$ & 1000 & $\begin{array}{l}\text { Milling } \\
\text { machine }\end{array}$ \\
\hline 3 & & $12-20$ & $\begin{array}{c}\text { FDM } \\
\text { machine }\end{array}$ & 95243.81 & 4.16 & 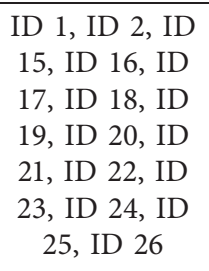 & $\begin{array}{l}\text { Surface } \\
\text { finish }\end{array}$ & 6000 & $\begin{array}{l}\text { Milling } \\
\text { machine }\end{array}$ \\
\hline 4 & & $20-25$ & $\begin{array}{c}\text { FDM } \\
\text { machine }\end{array}$ & 64643.81 & 3.15 & $\begin{array}{l}\text { ID } 1 \text {, ID } 2 \text {, ID } \\
15 \text {, ID } 16, \text { ID } \\
17, \text { ID } 18 \text {, ID } \\
23 \text {, ID } 24 \text {, ID } \\
25 \text {, ID } 26\end{array}$ & $\begin{array}{l}\text { Surface } \\
\text { finish }\end{array}$ & 5000 & $\begin{array}{l}\text { Milling } \\
\text { machine }\end{array}$ \\
\hline 5 & & $25-30$ & $\begin{array}{c}\text { FDM } \\
\text { machine }\end{array}$ & 56607.30 & 2.45 & $\begin{array}{l}\text { ID } 1, \text { ID } 2, \text { ID } \\
7, \text { ID } 9, \text { ID } 15 \\
\text { ID } 16, \text { ID } 17 \\
\text { ID } 18\end{array}$ & $\begin{array}{c}\text { Surface } \\
\text { finish }\end{array}$ & 5000 & $\begin{array}{l}\text { Milling } \\
\text { machine }\end{array}$ \\
\hline 6 & & $30-34$ & $\begin{array}{c}\text { FDM } \\
\text { machine }\end{array}$ & 28657.52 & 1.51 & $\begin{array}{l}\text { ID } 1, \text { ID } 2, \text { ID } \\
3, \text { ID } 4, \text { ID } 5 \text {, } \\
\text { ID } 6, \text { ID } 7, \text { ID } \\
8, \text { ID } 9, \text { ID } 15 \text {, } \\
\text { ID } 16, \text { ID } 17, \\
\text { ID } 18\end{array}$ & $\begin{array}{l}\text { Surface } \\
\text { finish }\end{array}$ & 4000 & $\begin{array}{l}\text { Milling } \\
\text { machine }\end{array}$ \\
\hline 7 & & $34-40$ & $\begin{array}{c}\text { FDM } \\
\text { machine }\end{array}$ & 29786.28 & 2.37 & $\begin{array}{l}\text { ID } 1 \text {, ID } 2 \text {, ID } \\
3, \text { ID } 4, \text { ID } 5 \text {, } \\
\text { ID } 6, \text { ID } 7 \text {, ID } \\
8, \text { ID } 9, \text { ID } 13 \text {, } \\
\text { ID } 14, \text { ID } 15 \text {, } \\
\text { ID } 16, \text { ID } 17, \\
\text { ID } 18\end{array}$ & $\begin{array}{l}\text { Surface } \\
\text { finish }\end{array}$ & 8000 & $\begin{array}{l}\text { Milling } \\
\text { machine }\end{array}$ \\
\hline
\end{tabular}

improvement in probe distance was observed with an increase in the number of iterations. Therefore, a maximum number of iterations of 2000 was selected as the stopping criterion of the proposed GA.
The best sequence obtained from the GA was 5-6-3-7-10-19-8-2-4, which corresponded to the minimum probe travel distance of $617.23 \mathrm{~mm}$ among all features. Initially, when the measurement path was selected randomly, the traveling distance 


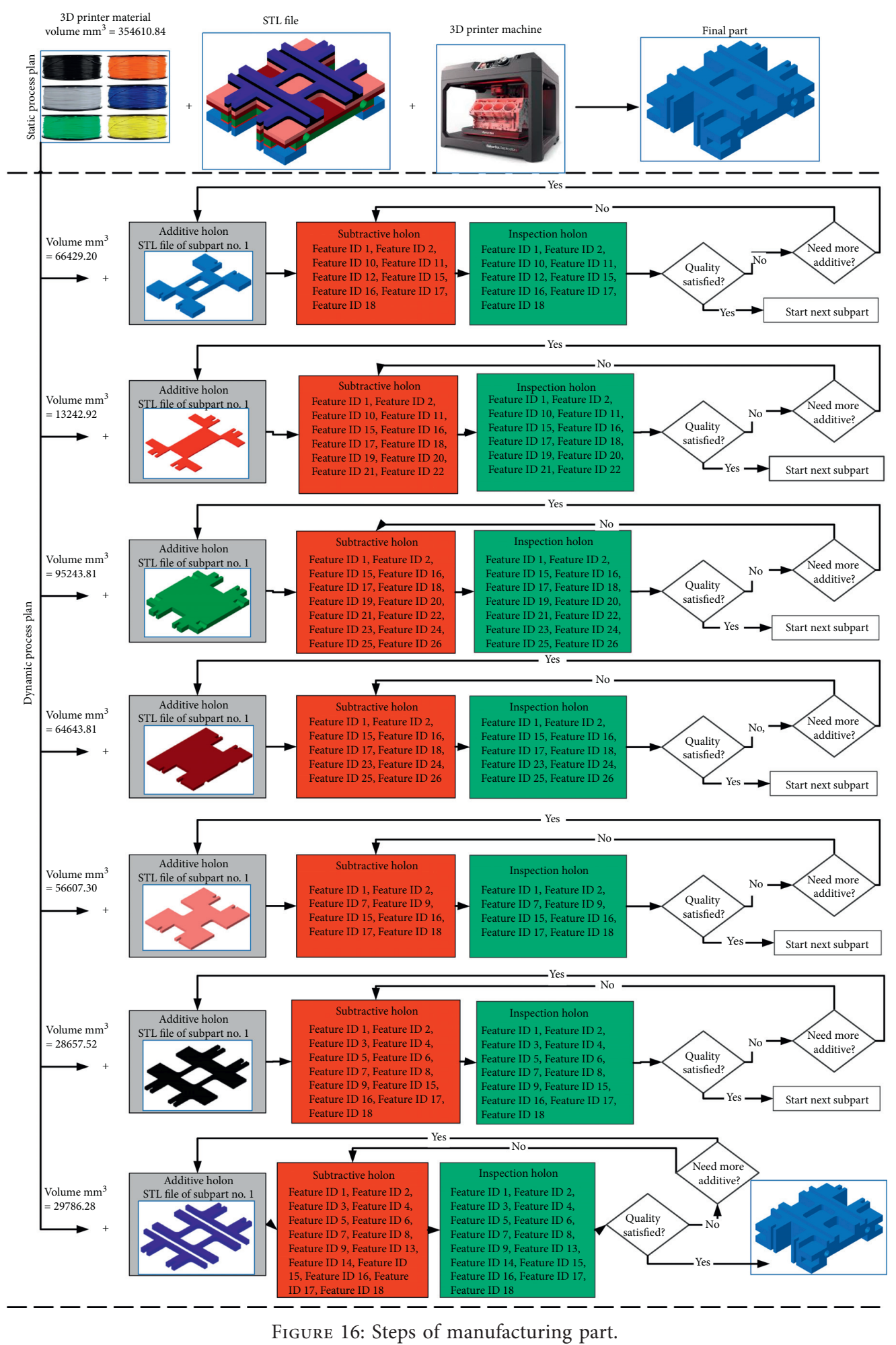

was $1007.3 \mathrm{~mm}$ and the coordinate measuring machine (CMM) running time was $6 \mathrm{~min} 32 \mathrm{~s}$. However, after the application of GA, the travel path of the probe decreased by $38.72 \%$, from 1007.3 to $617.23 \mathrm{~mm}$, while the CMM operation time was significantly reduced from $6 \mathrm{~min} 32 \mathrm{~s}$ to $4 \mathrm{~min} 19 \mathrm{~s}$. A time reduction of almost $33.93 \%$ was observed during the actual measurement of the part.
Although the CPU time also increased with an increasing number of iterations, this increase was negligible as compared with the reduction in the CMM operation time.

From the previous data, the best setup was the orientation no. 2, and depending on the peaks of all features, the whole part was divided to seven subparts within values as shown in Table 13. 
The dynamic process plan sequence acquired for the test part can be seen in Figure 16. As depicted in Figure 16, the entire part was first divided into subparts based on different peaks. Each subpart was fabricated in an additive fashion. Then, the subtractive operation was employed to obtain accurate features depending on the quality requirement. The inspection was also carried out simultaneously to decide if the subpart needed a subtractive operation or not.

\section{Conclusion}

An efficacious hybridization of additive, subtractive, and inspection processes can be accomplished through a vital link known as CAPP. Indeed, the most relevant and invaluable CAPP can be achieved through the optimization of its various components. Henceforth, in this work, different approaches were employed to obtain the most appropriate CAPP for the hybrid process, which could manufacture parts efficiently and effectively. Consequently, mathematical models were utilized to optimize part orientation and minimize additive and subtractive times. The GA was also used to achieve the shortest measurement time. An implementation of the introduced methodology has also been presented by using a test part case study for demonstrating its performance. Certainly, the optimized CAPP resulted in an adequate and the most competent hybrid process.

This paper has indeed developed a significant understanding and knowledge regarding the CAPP of the hybrid process. It would facilitate the users to acquire a most convenient strategy, to enable accurate and efficient hybrid fabrication of a given component. The primary contribution of this work pertains to the development of an optimized CAPP for a combined additive, subtractive, and inspection processes, using mathematical models, rules, and metaheuristics. The generation of CAPP was initiated depending on the information of additive and subtractive processes, available resources, technological constraints, etc. The presented approach exhibited several benefits, including reduced fabrication time, minimal resource utilization, and lesser human interference. This approach also had a downside in addition to several benefits that will be explored in future research. This limitation was mainly correlated with the effective specification of the dimensional tolerances. This could be because the STEP file used to extract and recognize features did not provide adequate information about the number of points, their distribution, the evaluation algorithm, etc. Certainly, this problem becomes more complex with the presence of complicated features, such as cylinders and curved surfaces. The specification of dimensional tolerances is indeed a key obstacle in the development of an inspection process plan as part of the hybrid process. Furthermore, as this approach can only be used for prismatic parts, therefore the future work also aims to upgrade its application for cylindrical, round, and free-form components. A comprehensive FEA scheme involving both additive as well as subtractive manufacturing processes will also be established to further enhance the quality of process planning.

\section{Data Availability}

The data used to support the findings of this study are included within the article.

\section{Conflicts of Interest}

The authors declare that there are no conflicts of interest regarding the publication of this paper.

\section{Acknowledgments}

The authors are grateful to the Raytheon Chair for Systems Engineering for funding.

\section{References}

[1] D.-S. Choi, S. H. Lee, B. S. Shin et al., "Development of a direct metal freeform fabrication technique using $\mathrm{CO}_{2}$ laser welding and milling technology," Journal of Materials Processing Technology, vol. 113, no. 1-3, pp. 273-279, 2001.

[2] S. T. Newman, Z. Zhu, V. Dhokia, and A. Shokrani, "Process planning for additive and subtractive manufacturing technologies," CIRP Annals, vol. 64, no. 1, pp. 467-470, 2015.

[3] Z. Zhu, V. Dhokia, S. T. Newman, and A. Nassehi, "Application of a hybrid process for high precision manufacture of difficult to machine prismatic parts," The International Journal of Advanced Manufacturing Technology, vol. 74, no. 5-8, pp. 1115-1132, 2014.

[4] W. J. Sames, F. A. List, S. Pannala, R. R. Dehoff, and S. S. Babu, "The metallurgy and processing science of metal additive manufacturing," International Materials Reviews, vol. 61, no. 5, pp. 315-360, 2016.

[5] I. Gibson, D. W. Rosen, and B. Stucker, Additive Manufacturing Technologies: 3D Printing, Rapid Prototyping, and Direct Digital Manufacturing, Springer, Berlin, Germany, 2014.

[6] K. P. Karunakaran, S. Suryakumar, V. Pushpa, and S. Akula, "Low cost integration of additive and subtractive processes for hybrid layered manufacturing," Robotics and Computer-Integrated Manufacturing, vol. 26, no. 5, pp. 490-499, 2010.

[7] Matsuura, LUMEX 2015, Avance-25, http://www.matsuura. co.jp/english/contents/products/lumex.html.

[8] P. Kulkarni and D. Dutta, "On the integration of layered manufacturing and material removal processes," Journal of Manufacturing Science and Engineering, vol. 122, no. 1, pp. 100-108, 2000.

[9] M. F. E. Kashouty, A. E. W. Rennie, and M. Ghazy, "Assessing additive and subtractive manufacturing technologies for the production of tools in the automotive industry," 2018.

[10] L. Ren, T. Sparks, J. Ruan, and F. Liou, "Integrated process planning for a multiaxis hybrid manufacturing system," Journal of Manufacturing Science and Engineering, vol. 132, no. 2, Article ID 021006, 2010.

[11] F. Liou, K. Slattery, M. Kinsella, J. Newkirk, H.-N. Chou, and R. Landers, "Applications of a hybrid manufacturing process for fabrication of metallic structures," Rapid Prototyping Journal, vol. 13, no. 4, pp. 236-244, 2007.

[12] J. Ruan, K. Eiamsa-Ard, and F. W. Liou, "Automatic process planning and toolpath generation of a multiaxis hybrid manufacturing system," Journal of Manufacturing Processes, vol. 7, no. 1, pp. 57-68, 2005.

[13] A. I. Shabaka and H. A. ElMaraghy, "A model for generating optimal process plans in RMS," International Journal of 
Computer Integrated Manufacturing, vol. 21, no. 2, pp. 180$194,2008$.

[14] X.-L. Jia, J.-X. Xu, Z.-M. Zhang, and N.-K. Huang, "The research on representation and processing of process knowledge based on object-oriented modeling," in Proceedings of the 2003 International Conference on Machine Learning and Cybernetics, IEEE Cat. No. 03EX693, pp. 657-660, Xi'an, China, 2003 November.

[15] A. N. Ahsan, M. A. Habib, and B. Khoda, "Resource based process planning for additive manufacturing," ComputerAided Design, vol. 69, pp. 112-125, 2015.

[16] J. Um, M. Rauch, J.-Y. Hascoët, and I. Stroud, "STEP-NC compliant process planning of additive manufacturing: remanufacturing," The International Journal of Advanced Manufacturing Technology, vol. 88, no. 5-8, pp. 1215-1230, 2017.

[17] V. T. Le, H. Paris, and G. Mandil, "Process planning for combined additive and subtractive manufacturing technologies in a remanufacturing context," Journal of Manufacturing Systems, vol. 44, pp. 243-254, 2017.

[18] A. M. Aboutaleb, L. Bian, N. Shamsaei, S. M. Thompson, and P. K. Rao, "Multi-objective process optimization of additive manufacturing: a case study on geometry accuracy optimization," in Proceedings of the Annual International Solid Freeform Fabrication Symposium, Austin, TX, USA, 2016 January.

[19] T. Reiher and R. Koch, "Product optimization with and for additive manufacturing," in Proceedings of the 27th Annual International Solid Freeform Fabrication Symposium, p. 10, Austin, TX, USA, 2016.

[20] R. Udroiu and A. Nedelcu, "Optimization of additive manufacturing processes focused on 3D Printing," in Rapid Prototyping Technology-Principles and Functional Requirements, IntechOpen, London, UK, 2011.

[21] H.-S. Byun and K. H. Lee, "Determination of the optimal build direction for different rapid prototyping processes using multi-criterion decision making," Robotics and ComputerIntegrated Manufacturing, vol. 22, no. 1, pp. 69-80, 2006.

[22] A. Kamrani, E. A. Nasr, A. Al-Ahmari, O. Abdulhameed, and S. H. Mian, "Feature-based design approach for integrated $\mathrm{CAD}$ and computer-aided inspection planning," The International Journal of Advanced Manufacturing Technology, vol. 76, no. 9-12, pp. 2159-2183, 2015.

[23] D. Homar and F. Pušavec, "The development of a recognition geometry algorithm for hybrid - subtractive and additive manufacturing," Strojniški Vestnik-Journal of Mechanical Engineering, vol. 63, no. 3, pp. 151-160, 2017.

[24] A. M. Al-Ahmari, O. Abdulhameed, and A. A. Khan, "An automatic and optimal selection of parts orientation in additive manufacturing," Rapid Prototyping Journal, vol. 24, no. 4, pp. 698-708, 2018.

[25] O. Abdulhameed, A. M. Al-Ahmari, W. Ameen, and S. H. Mian, "Novel dynamic CAPP system for hybrid additive-subtractive-inspection process," Rapid Prototyping Journal, vol. 24, no. 6, pp. 988-1002, 2018.

[26] E. A. Nasr and A. K. Kamrani, Computer-Based Design and Manufacturing: An Information-Based Approach, Springer, Berlin, Germany, 2007.

[27] A. Cattenone, S. Morganti, G. Alaimo, and F. Auricchio, "Finite element analysis of additive manufacturing based on fused deposition modeling: distortions prediction and comparison with experimental data," Journal of Manufacturing Science and Engineering, vol. 141, no. 1, 17 pages, Article ID 011010, 2019.
[28] S. H. Mian, M. A. Mannan, and A. M. Al-Ahmari, "The influence of surface topology on the quality of the point cloud data acquired with laser line scanning probe," Sensor Review, vol. 34, no. 3, pp. 255-265, 2014.

[29] H. Ramaswami, S. Kanagaraj, and S. Anand, "An inspection advisor for form error in cylindrical features," The International Journal of Advanced Manufacturing Technology, vol. 40, no. 1, pp. 128-143, 2009.

[30] P. V. Sukhatme, B. V. Sukhatme, S. Sukhatme et al., Sampling Theory of Surveys with Applications, Iowa State University Press, Ames, IA, USA, 1984

[31] A. Barari and S. Mordo, "Effect of sampling strategy on uncertainty and precision of flatness inspection studied by dynamic minimum deviation zone evaluation," International Journal of Metrology and Quality Engineering, vol. 4, no. 1, pp. 3-8, 2013. 